\title{
The ASR mechanism of reactive aggregates in concrete and its mitigation by fly ash: A critical review
}

\author{
Ashish Kumer Saha ${ }^{1 *}$, Md Nabi Newaz Khan ${ }^{1}$, Prabir Kumar Sarker ${ }^{2}$, Faiz Ahmed Shaikh', \\ Alokesh Pramanik ${ }^{3}$ \\ ${ }^{1} \mathrm{PhD}$ student, ${ }^{2}$ Associate Professor, ${ }^{3}$ Lecturer \\ School of Civil and Mechanical Engineering, Curtin University, GPO Box U1987, Perth, WA 6845, \\ Australia. \\ *Corresponding author: Email: a.saha@postgrad.curtin.edu.au
}

\begin{abstract}
Alkali-silica reaction (ASR) of reactive aggregates is a major durability concern of concrete. The use of fly ash as a supplementary cementing material (SCM) shows a reliable way to control ASR expansion. This paper investigates the recent findings on effects of coal fly ash as a SCM on ASR of reactive aggregates. ASR is the reaction of amorphous silica of aggregates with highly alkaline pore solution in the binder matrix producing an expansive gel. The use of fly ash as cement replacement reduces $\mathrm{pH}$ of the pore solution by alkali binding and thus reduces the aggregate dissolution rate and swelling pressure of the ASR gel. The efficiency of fly ash primarily depends on its chemical composition with low calcium fly ash being more effective in mitigation of ASR expansion. Based on the available literature, this paper also analyses the ASR mitigation mechanisms of fly ash and provides some recommendations for future research. The degree of aggregate reactivity measurement, effect of alumina in fly ash, swelling properties of ASR gel in presence of fly ash and the long-term alkali contribution of fly ash on ASR are of particular importance.
\end{abstract}

Keywords: Aggregate dissolution, alkali binding, alkali-silica reaction, fly ash, pore solution, reactive aggregates.

\section{Introduction}

Concrete is the most widely used construction material in the world. There are various reasons behind the popularity of concrete as the first choice of building material, such as durability, low relative cost, low maintenance and high fire resistance. However, exposure to an aggressive environmental condition for an extended period of time can cause deterioration of concrete. The lifespan of concrete can be reduced by various factors, such as reinforcement corrosion, alkali-silica reaction (ASR), carbonation and leaching. Among all the concrete damage mechanisms, ASR is one of the severe durability related issues for concrete that may cause extensive damage to concrete structures. Repair works of structures affected by ASR can be very complicated, expensive and time-consuming. In 1940, Stanton [1] pointed out that concrete can suffer deleterious expansion due to the use of reactive aggregates. The author further observed the effectiveness of using pozzolans as partial replacement of cement to reduce ASR [2]. Since then, researchers reported about ASR expansion in concrete structures 
in different parts of the world. In 1980, Cole et al. [3] found dams in Australia suffering from deleterious cracking due to a similar phenomenon. Ono [4] noticed concrete structures in Japan showing significant cracking due to deleterious expansion by ASR. Swamy [5] reported the failure of airfield pavements in New Zealand due to ASR expansions. Recently, structural damages due to ASR have been identified in Seabrook nuclear power in the USA [6] and Mactaquac Dam in Canada [7]. Though the fundamental concept of ASR in structural concrete has been known to the scientific community for a few decades, there are still cases of modern structures suffering from severe damage due to this deleterious expansion which proves the complexity of ASR mechanism.

There are several factors that influence this mechanism significantly. Silica is present in amorphous form in reactive aggregates such as opaline silica, chalcedony, cristobalite, tridymite, volcanic glasses, cryptocrystalline quartz, strained quartz etc. and the pore solution of cement binder matrix is highly alkaline [8]. The reaction of amorphous silica of aggregates with alkaline pore solution produces a gel that can cause expansion and cracking of concrete [9]. Thus the alkali content of cement plays a vital role in ASR expansion. It is noted that the higher concentrations of alkali in cement can result in higher expansions due to ASR [10]. The use of low alkali cement has been suggested by different standards to minimise ASR. However, cement with alkali content lower than $0.6 \%$ could not reduce the expansion below the limiting value. This is often because of the alkali contribution by aggregates [10, 11]. The amorphous structure of manufactured aggregate such as volcanic glass, unwashed marine sand, feldspar, mica, clay minerals and zeolites can increase the alkalinity of pore solution of concrete, hence caused considerable ASR expansion [12-17]. In addition, applying impermeable coatings into structure was not successful to mitigate the expansion due to moisture ingress from the surrounding environment. Consequently, the alkali of cement and reactive aggregates cause deleterious expansion with the available moisture present in the concrete pore solution [18].

The use of supplementary cementing materials (SCM) has been found to be the most efficient way of ASR mitigation technique based on the available research conducted so far. In this connection, extensive research has been carried out using different types of SCM such as silica fume (SF), fly ash (FA), ground granulated blast furnace slag (GGBFS) and other pozzolans [19-25].

It has been found that SF mixed concrete shows high strength with less porosity than the conventional concrete [19]. Furthermore, SF is able to reduce the hydroxyl ion from pore solution and hence reduce the ASR expansion [20-22]. Aquino et al. [23] tested ASR expansion by accelerated mortar bar test using SF as a $10 \%$ replacement of cement and found $50 \%$ reduction in expansion as compared to control specimens after 28 days of testing. Similarly, Fournier et al. [24] reported that the use of $7.5 \% \mathrm{SF}$ as a cement replacement kept the expansion of concrete prisms within the allowable limit even after a testing period of 10 years. In addition, Oberholster [25] showed that 3.5\% SF mixed concrete exhibited $0.25 \%$ expansion whereas concrete containing 7\% SF exhibited $0.07 \%$ expansion after a testing period of 7 years. In contrast, Shehata \& Thomas [19] pointed out that 5\% SF may reduce alkalinity at the early ages with a gradual increase over a period of 2 to 3 years. 
GGBFS has been well known to produce concrete with high strength, low permeability, high density, and resistance to chloride ion penetration, sulphate attack and corrosion of reinforcing steel [26-29]. The effectiveness of GGBFS on ASR mitigation was been studied extensively in past decade [26,30-35]. It is noticed that usually a large volume of cement replacement is required for ASR mitigation by GGBFS. Saha \& Sarker [17] showed that 30\% replacement of cement by GGBFS was not enough to reduce the ASR expansion ferronickel slag fine aggregate below the allowable limit. On the other hand, Thomas [33] reported that more than $50 \%$ cement replacement by GGBFS was required in order to reduce the expansion of concrete prisms below $0.04 \%$ after the two years of testing when reactive Spratt fine aggregate was used. The concentration of alkali in pore solution reduced significantly by using $50 \%$ GGBFS as a cement replacement. As a result, expansion did not exceed the allowable limit [34]. Similarly, according to accelerated mortar bar test results conducted by Choi \& Choi on FNS aggregates [31], 60\% cement replacement was required to reduce the ASR expansion below the allowable limit.

Fly ash (FA) is a well-recognised supplementary cementing material, used in concrete productions in different parts of the world. The use of FA as partial replacement of cement can produce concrete of high strength and improved durability [36-41]. Oner et al. [41] investigated the optimum quantity of FA in concrete and it was suggested that cement can be replaced by FA up to $40 \%$. Concrete incorporated with FA showed high-performance due to its significant pozzolanic reaction where calcium hydroxide produced from cement hydration reacts with the amorphous silica present in FA and forms calcium silicate hydrate $(\mathrm{C}-\mathrm{S}-\mathrm{H})$, which has excellent binding properties [41]. The use of FA in concrete has also been studied extensively as an ASR mitigation measure during the last decades. Therefore, this paper reviews the latest advancements on the knowledge of ASR mechanism and contribution of the ingredients of concrete on this deleterious expansion. The use of FA in concrete as an ASR mitigation technique has been discussed in details and the needs for further research have been identified.

\section{ASR mechanism}

ASR takes place between the reactive silica of aggregates and the alkaline solutions in micropores of concrete. The primary sources of alkali are the binder, aggregates and the surrounding environment. Alkalis generated from alkali metal ions take part in reactions with water to form soluble alkali hydroxides [42]. The silica present in aggregates in the form of quartz is chemically inert. However, the poorly crystalline silica has the affinity to react with water and generate amorphous hydrous silica. Some examples of poorly crystallised silica are opal, chert, chalcedony and glasses [43]. Portlandite $\left(\mathrm{Ca}(\mathrm{OH})_{2}\right)$ and calcium silicate hydrate (C-S-H) are produced by the reaction of cement with water in the hydration process. This $\mathrm{Ca}(\mathrm{OH})_{2}$ contributes hydroxyl ions $\left(\mathrm{OH}^{-}\right)$into the pore solution [43]. The ASR mechanism consists of three major stages of chemical reaction as shown by Eqs. 1 to 3. At the initial stage of ASR, the hydroxyl ions undergo reaction with Si-O-Si bonds of amorphous silica to produce silicic acid ( $\mathrm{Si}-\mathrm{OH})$ and alkali silicate $(\mathrm{Si}-\mathrm{O}-\mathrm{R})$, where $\mathrm{R}^{+}$represents the alkali metal ions. Then the silicic acid reacts with the hydroxyl ions $\left(\mathrm{OH}^{-}\right)$and metal alkali that forms alkali silicate hydrate by liberating water. Finally, the expansion occurs due to hydration of the alkali silicate 
gel [43-46]. Later, the hydrated alkali-silicate gel gets defused from aggregate to cement paste and undergoes reaction with the calcium ions $\left(\mathrm{Ca}^{2+}\right)$. This generates alkali-calcium-silicate hydrate gel [47-50]. These products absorb moisture from the surroundings and expand in volume. Excessive expansion can cause cracking of aggregate and cement paste to initiate degradation of concrete.

$\equiv \mathrm{Si}-\mathrm{O}-\mathrm{Si} \equiv+\mathrm{OH}^{-}+\mathrm{R}^{+} \rightarrow \equiv \mathrm{Si}-\mathrm{O}-\mathrm{R}+\mathrm{H}-\mathrm{O}-\mathrm{Si} \equiv$

$\equiv \mathrm{Si}-\mathrm{O}-\mathrm{H}+\mathrm{OH}^{-}+\mathrm{R}^{+} \rightarrow \equiv \mathrm{Si}-\mathrm{O}-\mathrm{R}+\mathrm{H}_{2} \mathrm{O}$

$\equiv \mathrm{Si}-\mathrm{O}-\mathrm{R}+\mathrm{nH}_{2} \mathrm{O} \quad \rightarrow \quad \equiv \mathrm{Si}_{-}-\mathrm{O}^{-}-\left(\mathrm{H}_{2} \mathrm{O}\right)_{\mathrm{n}}+\mathrm{R}^{+}$

\subsection{Effect of aggregate characteristics}

Aggregates play a significant role in ASR expansion. Depending on the reactivity of aggregates, it can be classified into two categories. Aggregates mostly containing amorphous silica are classified as reactive and those containing crystalline silica are classified as nonreactive. The reactive aggregates may also consist of meta-stable crystals, microcrystalline silica and other crystalline forms containing many lattice defects, residual strains, or internal micro-cracks [51]. The reactive aggregates can be found from natural sources as well as from industrial processes as by-products. For instance, obsidian, which is a volcanic glass exhibits deleterious alkali silica reaction. The lava coming out from a volcano cool down very quickly, as a result, the formation of silica is found to be amorphous rather than in crystalline structure [52]. Similar phenomenon can also be observed in reactive industrial by-products. It has been found that rapid cooling of molten Nickle slag by water results in formation of amorphous silica causing susceptibility to ASR, whereas, slowly cooled nickel slag by air flow is found to be less reactive or non-reactive. The slow cooling process leads to formation of crystalline silica, as a result, the aggregate is found to be non-reactive [31]. Similarly, production process of glass also goes through a rapid cooling process. As a result, glass particles contain a significant amount of amorphous silica that causes ASR expansion when used as aggregate [53-54]. Therefore, the amorphous silica content of an aggregate indicates the potential ASR susceptibility of that aggregate. Table 1 shows the amorphous silica contents of some reactive aggregates used in different studies and the corresponding expansions in accelerated mortar bar tests (AMBT) and concrete prism tests (CPT). A relationship can be seen between expansion and the percentage of amorphous silica present in the aggregates. It can be seen that expansion generally increased with the increase of amorphous silica content in aggregates. However, the correlation is not proportional. For example, three different aggregates such as FNS, glass and sintered silica fume exhibited similar expansion, which is about $0.65 \%$ in AMBT even though the reactive silica content was $50 \%, 73 \%$ and $85 \%$, respectively. Furthermore, concrete samples with Chinese limestone containing only $4.6 \%$ amorphous silica exhibited ASR expansion of $0.064 \%$ CPT which exceeds the allowable limit of $0.03 \%$ suggested by the ASTM C1293 standard [61]. Therefore, amorphous silica content of aggregates acts as a governing factor of ASR expansion. 
Figs. 1(a) to 1(c) show the photos of typical volcanic glass [62], nickel slag [63], recycled glass aggregates [64]. It can be seen that volcanic glass and nickel slag aggregates are similar dark colour $[31,65]$. Both of the particles possess a high level of angularity in physical appearance. Some siliceous limestones are found to be alkali-silica reactive due to the presence of amorphous siliceous phase. Siliceous limestone such as kieselkalk, tournaisian and spratt are found to exhibit alkali silica reactions. Generally, kieselkalk is found in Switzerland, tournaisian aggregate is found in Belgium and Spratt aggregate is found in Canada [66-68]. In addition, aggregates found from quarry operations, such as basalt is found as alkali silica reactive when applied in concrete as aggregate [69].

The reactivity of an aggregate also depends on its size. Aggregates with smaller particles give higher surface area that increases ASR expansion [1, 70]. However, Poyet et al. [71] found that very small size reactive aggregates could also reduce ASR expansion. This is because very finely ground particles of reactive aggregate may take part in the pozzolanic reaction and reduce alkalinity of the pore solution. In the reaction process, the silicate ion of reactive aggregate is first detached by the hydroxyl ion of pore solution which is then reacted with soduim or potasium ions to form an alkali-silicate gel. Since there is adequate calcium available in concrete at the early ages, the alkali-silicate gel is quickly converted to calciumsilicate-hydrate $(\mathrm{C}-\mathrm{S}-\mathrm{H})$ in the pozzolanic reaction. On the other hand, for large reactive aggregates, it takes years to occur ASR in concrete. Since there is less calcium available for reaction in matured concrete, the alkali-silicate gel in this case is not quickly converted to $\mathrm{C}$ $\mathrm{S}-\mathrm{H}$ and absorption of water by the gel causes expansion. Therefore, aggregate containing amorphous silica may contribute to strength by pozzolanic reaction at early ages or may case ASR expansion at matured ages depending on the size.

Rajabipour et al. [72] reported that soda lime glass aggregates of size ranging from 1.18 $\mathrm{mm}$ to $2.36 \mathrm{~mm}$ showed maximum expansion. Furthermore, Bažant and Steffens [46] suggested that the swelling pressure of ASR gel depends on particle diameter. The maximum pressure was observed for particles with the size of 2 to $3 \mathrm{~mm}$. However, Maraghechi et al. [73] argued that ASR expansion increases with the increase of particle size because larger particles consist of the greater amount of reactive microcracks. Furthermore, Ichikawa [74] confirmed the effectiveness of excessive amount of reactive aggregates above the pessimum proportion can reduce ASR expansion. According to the author, there were two primary reasons behind this phenomenon. Firstly, calcium hydroxide was consumed by the alkali silicates with the increase of reactive aggregates. As a result, formation of the reaction rims was reduced. Secondly, reduction of alkali hydroxides for individual aggregate particles reduced the reaction. Besides, the pessimum proportion for a different type of aggregate can be very hard to predict. Different researchers suggested different pessimum aggregates size which can exhibit the highest expansion [46, 72]. With the current standard test such as AMBT and CPT it is difficult to correlate the expansion with the pessimum aggregate proportion because both the tests use specific aggregate gradation for testing [59-61]. Therefore, there is a scope of further investigation into the effect of aggregate size on ASR expansion. 
The pore solution alkalinity is a governing factor in ASR. Cement hydration contributes to a significantly high alkalinity to the pore solution. Therefore, reducing the alkalinity of pore solution is complicated. In addition, lower alkalinity in pore solution can cause carbonation and corrosion of the reinforcement. Besides, aggregates can also supply alkali to the binder matrix to amplify the alkali silica reaction. It is reported that reactive aggregate such as volcanic aggregates, glass aggregate, and non-reactive aggregates such as granite, mica, zeolites, clay minerals and feldspars can release alkali and increase the $\mathrm{pH}$ of pore solution $[6,9,73,75-76]$. Grattan-Bellew [77] pointed out that the alkali released from aggregates can be a significant reason behind the ASR expansion of concrete. The amount of alkali released from an aggregate depends on its mineral structure. The mechanism of alkali dissolution from the aggregates was attributed to the cation exchange with the calcium hydroxide of pore solution [77]. Furthermore, Goguel [78] showed that the rapid cooling leads to the poor crystallisation of minerals in an aggregate that can release a high concentration of alkali $\left(1 \% \mathrm{Na}_{2} \mathrm{O}\right)$ into the pore solution, whereas well-crystallized minerals released less amount of alkali $\left(0.1 \% \mathrm{Na}_{2} \mathrm{O}\right)$.

On the other hand, it has been observed that there are different types of supplementary cementing materials ( $\mathrm{SCM}$ ) that contain a significant amount of alkali, often more than $6 \%$ by mass which is the allowable limit for OPC [79]. Nevertheless, SCMs can reduce the alkalinity of pore solution by alkali binding [33]. However, this ability of alkali binding depends on the alkali content of a SCM. Shehata and Thomas [80] reported that low calcium fly ash could increase the alkali-binding capacity of C-S-H as compared to high calcium fly ash. Similarly, Bhatty and Greening [81] proved that alkali retention of C-S-H gel is increased by lowering the calcium to silicon $(\mathrm{Ca} / \mathrm{Si})$ ratio when fly ash is used as a SCM. Hong and Glasser [82] pointed out that the addition of alumina in C-S-H gel formed C-A-S-H, which improved the alkali binding capacity. Uchikawa et al. [83] showed that the effect of the pozzolanic reaction of fly ash could reduce the alkalinity of the pore solution. Fig. 2 shows the relationships between the available alkalis in pore solution with respect to its chemical composition [80]. It can be seen that a linear correlation exists between the amount of alkali release from the binder with respect to its chemical combination particularly alkali, calcium and silica content $\left(\mathrm{Na}_{2} \mathrm{O}_{\mathrm{e}}\right.$ $\times \mathrm{CaO} / \mathrm{SiO}_{2}$ ). From Fig. 2, it is noticeable that the available alkali in pore solution gradually decreased with the increment of silica content. As a result, this alkali release phenomenon can lead to the deterioration of concrete due to ASR at the later stages of its service period. According to the study conducted by Ideker et al. [84], a high alkali SCM mixed concrete did not exhibit any sign of expansion for a period of ten years in normal environmental exposure. However, the authors found significant cracking after ten years, though these mix combination did not show any sign of ASR expansion in concrete prism test (CPT).

From the above discussion, it can be seen that both aggregate and binder contribute to the pore solution alkalinity, which causes the ASR expansion. On the other hand, a binder with low $\mathrm{Ca} / \mathrm{Si}$ ratio results in low alkalinity of the pore solution. Therefore, aggregate with low alkali content and binder with high silica content are desirable to reduce the ASR expansions.

\subsection{Role of calcium}


The amount of calcium has a noticeable effect on ASR expansion of concrete. Different approaches have been documented to exhibit the dependency of portlandite $\left(\mathrm{Ca}(\mathrm{OH})_{2}\right)$ in ASR. Earlier, Chatterji [85] described that the presence of high amount of portlandite in pore solution formed a semi-permeable layer around the aggregates, which allowed the hydroxyl ion penetration into the reactive silica grain but prevented the silica diffusion from the reactive site. As a result, cracking and expansion occurred in the test specimens. Then, an experimental work carried out by Wang and Gillott [86] showed that calcium acts as a buffer to maintain the $\mathrm{pH}$ of pore solution by releasing hydroxyl ion in pore. In addition, Thomas et al. [87] found that the alkali silicate gel formed due to aggregate dissolution is fluid in nature and has the capability to get dispersed in the binder matrix. However, the addition of calcium replaces the alkali from this gel, which is a more viscous product that has the affinity to expand by absorbing water. In contrast, Powers and Steinour [88] reported that low concentration of portlandite formed expansive alkali silica gel, whereas a high concentration of portlandite formed nonexpansive calcium-alkali-silica gel. The chemical composition of ASR products can be different depending on the location of the gel. For instance, a gel located in pores and cracks contains a higher amount of calcium as compared to the gel in the reactive aggregates [50,89]. Therefore, it is difficult to correlate the chemical composition and the expansion of ASR products. Vayghan et al. [51] found significant expansion for sufficient concentration of the calcium in a binder matrix. The authors explained that viscosity and yield strength of ASR gel increased due to the presence of calcium. As a result, greater stress was caused by the gel expansion. However, Lehmann et al. [90] demonstrated that the water binding capacity of ASR gel not only depends on calcium content but also on calcium to silicon ratio $(\mathrm{Ca} / \mathrm{Si})$. According to their study, ASR gel bound water both physically and chemically. Fig. 3 shows the water binding capability of ASR gel with respect to $\mathrm{Ca} / \mathrm{Si}$ ratio as found by Lehmann et al. [90]. As seen in Fig 3(a), the chemically bound water gradually decreased with the increment of the $\mathrm{Ca} / \mathrm{Si}$ ratio. The physically bound water of ASR gel was found to be maximum when the $\mathrm{Ca} / \mathrm{Si}$ was in the range of 0.2 to 0.3 , with a decreasing trend when $\mathrm{Ca} / \mathrm{Si}$ was outside this range, as seen in Fig 3(b).

From the above discussion, it is seen that calcium content of binder plays an important role in ASR expansion. Lowering the portlandite can reduce the ASR expansion significantly; however, concrete mix with too low portlandite might suffer from very slow strength development. Therefore, a balance needs to be established so that deleterious ASR expansion can be mitigated with the minimum compromise with strength properties of concrete.

\section{Effect of fly ash}

Fly ash is a widely known SCM. Extensive investigation has been conducted on the use fly ash as an ASR mitigation measure. Although use of fly ash has been studied extensively as an ASR mitigation technique, contradictory opinions on its effect can be observed among researchers. Therefore, the mechanism associated with fly ash to mitigate ASR expansion is categorised in the following sections and discussed in details.

\subsection{Effect of chemical composition}


The chemical composition of fly ash plays a vital role on its ASR mitigation mechanism. According to ASTM C618 [91], a fly ash containing low alkali and low calcium is classified as class $\mathrm{F}$ and those with high alkali and high calcium content belong to class $\mathrm{C}$. It has been reported in several studies that class $\mathrm{F}$ fly ash showed better performance in ASR mitigation as compared to class $\mathrm{C}$ fly ash [80, 55, 92-93]. Therefore, chemical analysis of fly ash is considered as an initial step to determine its effectiveness as an ASR mitigation measure. Table 2 compares the effect of fly ash types and replacement level on ASR based on available literature. It can be seen that relatively lower proportions of class F fly ash were found adequate to mitigate the expansion due to ASR in both AMBT and CPT. According to the testing standards, the allowable expansion limit is $0.04 \%$ after two years for CPT [61] and $0.01 \%$ after 16 days for AMBT [59, 60]. However, a higher cement replacement by class $\mathrm{C}$ fly ash was required to keep expansion within the allowable limit. The chemical composition of class F fly ash plays a vital role in this regard. Class F fly ash contains high amount of amorphous silica and significantly low amount of lime. As a result, the presence of high amorphous silica consumes the portlandite from pore solution [19]. Consequently, the utilization of portlandite from pore solution causes reduction of its alkalinity [57]. On the other hand, class C fly ash has a higher amount of calcium oxide as compared to class $\mathrm{F}$ fly ash that eventually contributes to the generation of portlandite [94]. Furthermore, the amorphous silica of class F fly ash reduces porosity by the product of the pozzolanic reaction. As a result, less voids are available in class F fly ash mixed concrete to accumulate the viscous ASR gels [19, 55].

In addition, the expansions of samples not only depend on the calcium content of fly ash but also on the calcium oxide to silica $\left(\mathrm{CaO} / \mathrm{SiO}_{2}\right)$ ratio. Fig. 4 shows the relationship between $\mathrm{CaO} / \mathrm{SiO}_{2}$ ratio and expansion as reported by Shehata and Thomas [55]. It can be seen that the fly ashes with higher $\mathrm{CaO} / \mathrm{SiO}_{2}$ ratios showed higher expansions as compared to lower $\mathrm{CaO} / \mathrm{SiO}_{2}$ ratios.

Researchers have been studying to find a correlation between the alumina $\left(\mathrm{Al}_{2} \mathrm{O}_{3}\right)$ content in fly ash and ASR expansion. Though the presence of $\mathrm{Al}_{2} \mathrm{O}_{3}$ is stated to suppress ASR expansion, the available literature is limited to support the statement. Ramlochan et al. [97] reported that $\mathrm{Al}_{2} \mathrm{O}_{3}$ present in $\mathrm{SCM}$ was insufficient and ineffective to mitigate ASR expansion. The authors explained that formation of a large quantity of ettringite replaced the monosulphate in pore solution and started to expand. Nevertheless, high alumina fly ash alters the chemical composition of alite phase by providing a significant amount of $\mathrm{Al}^{3+}$ in CSH gel. Besides, Warner et al. [98] reported that $18 \%$ to $25 \%$ high alumina fly ash is more useful to reduce ASR expansion. The authors developed a relationship between expansion and alumina or silica content, as presented in Fig. 5. It can be seen that high alumina and silica fly ash specimens exhibited lower expansion as compared to the low alumina and silica fly ash specimens. As seen in Fig. 5(a), there is an exponential regression relationship between expansion and the total alumina and silica $(\mathrm{Al}+\mathrm{Si})$ content with a degree of determinacy of 0.83 for two different type of fly ash FA2 (class C) and FA3 (class F). On the other hand, Fig. 5 (b) shows that expansion gradually decreased with the increment of alumina content. It is also noticeable that a linear trend line has a degree of determinacy of 0.46 which is very low. In another study, Hong and Glasser [99] reported that high alumina fly ash has higher alkali 
binding capacity as compared to the low alumina fly ash. As a result, high alumina fly ash is stated to be more effective to reduce the alkalinity of the pore solution. Consequently, low expansion was observed by the use of high alumina fly ash.

Similarly, Shafaatian [100] attempted to evaluate the impact of alumina on ASR. The author used aluminium hydroxide $\mathrm{Al}(\mathrm{OH})_{3}$ as an admixture in a mortar to study its effect on alkali-silica reactivity. According to microstructural studies as presented in Fig. 6, the author observed that the addition of $\mathrm{Al}(\mathrm{OH})_{3}$ created an aluminosilicate layer around the aggregate surface which protected the aggregates from dissolution by the hydroxyl ions. Therefore, the author concluded that the addition of $\mathrm{Al}(\mathrm{OH})_{3}$ reduced ASR expansion significantly. Furthermore, Chappex and Scrivener [101] concluded that the alumina present in pore solution is absorbed by the silica surface of aggregate and hence reduce the decomposition of silica and retard the ASR expansion.

The effect of alkali content of fly ash on ASR expansion was reported by several researchers. Schumacher \& Ideker [102] observed that low alkali fly ash based samples exhibited less expansion than the high alkali fly ash based samples in AMBT. Similarly, Duchesne \& Bérubé [103] found that low alkali fly ash was more effective than high alkali fly ash to reduce the ASR expansion after more than 10 years of testing period, as shown in Fig. 7. It can be seen that both low alkali and high alkali fly ash showed relatively steady expansion up to 2 years of testing. It can be seen that $40 \%$ high alkali fly ash samples is completely ineffective against expansion, however, 20\% low alkali fly ash samples exhibited expansion within an acceptable limit of the ASTM C1293 Standard [61]. Similarly, Shehata and Thomas [55] illustrated the relationship between alkali content in fly ash and ASR expansion, as shown in Fig. 8. It can be seen that expansion increased gradually with the increment of alkali content. The sample containing a total alkali of $2.85 \mathrm{~kg} / \mathrm{m}^{3}$ showed expansion within the allowable limit, whereas, the other mixes with higher alkali contents exceeded the allowable limit. Thus, the high alkali fly ash was unable to keep expansion within the allowable limit. Therefore, for a similar level of cement replacement, low alkali fly ash is more effective than high alkali fly ash.

From the above discussion, it is evident that the chemical composition of fly ash carries a great significance in its ASR mitigation mechanism. High silica and low alkali class F fly ash is found to be the most effective ASR mitigation technique.

\subsection{Reduction of aggregate dissolution}

ASR is initiated with the aggregate dissolution process. At first, the alkali from pore solution attacks the amorphous silica bonds of the aggregate. Then, this generates alkali silicate gel, which absorbs moisture and expands that may cause cracking and reduction of strength $[19,55]$. Earlier, Dron \& Brivot $[47,48]$ noticed that aggregate dissolution process was mainly responsible for ASR and the authors linked the dissolution rate with the crystallinity and silanol/siloxane ratio of aggregate. Recently, Hernández-Cruz et al. [104] investigated the aggregate dissolution process by microtomography analysis. Fig. 9 presents the 3D image of 
ASR affected samples after different curing ages [104]. The authors reported that $1 \mathrm{M} \mathrm{NaOH}$ solution exposure resulted in numerous micropores and air voids due to aggregate dissolution at the initial stage. $D$ and $G$ indicate the reactive aggregates and pores filled with ASR gel respectively in the figure. Next, these micropores and the air voids were gradually filled by ASR gel that started the expansion. Afterwards, cracks are noticeably filled with ASR gel which are denoted by C. Finally, the specimens suffered from internal stress due to the expansion of these gels and introduced cracking.

Fly ash plays a significant role to mitigate this aggregate dissolution. Shafaatian et al. [58] studied the effectiveness of fly ash to mitigate the aggregate dissolution rate. The authors exposed soda-lime glass into $1 \mathrm{M} \mathrm{NaOH}$ solution at $80^{\circ} \mathrm{C}$ and recorded the mass loss at 7 and 14 days. Fig. 10 shows the mass loss of glass aggregates at 7 and 14 days [58]. It can be seen that the mass loss of glass aggregates significantly decreased when $10 \mathrm{~g}$ and $20 \mathrm{~g}$ fly ash was added into $1 \mathrm{M} \mathrm{NaOH}$ solution. At 14 days, the mass losses were $0.18 \mathrm{mg} / \mathrm{mm}^{2} 0.08 \mathrm{mg} / \mathrm{mm}^{2}$ and $0.06 \mathrm{mg} / \mathrm{mm}^{2}$ for no fly ash, $10 \mathrm{~g}$ fly ash and $20 \mathrm{~g}$ fly ash, respectively. Therefore, the mass loss of the aggregates significantly decreased with the addition of fly ash. The authors explained that fly ash reduced the alkali concentration at the aggregate surface by providing available silicate surface area which reacted with the available alkali in pore solution. As a result, the aggregate dissolution rate decreased significantly.

\subsection{Pore solution chemistry}

Fly ash has a significant influence on the pore solution to mitigate ASR. Firstly, fly ash reduces the alkalinity of pore solution by alkali binding. Diamond [105] measured the alkali concentration $\left(\mathrm{Na}^{+}\right.$and $\left.\mathrm{K}^{+}\right)$in pore solution of OPC paste and fly ash blended paste $(30 \%$ fly ash $+70 \%$ OPC). Fig. 11 shows the alkali concentration in pore solution of OPC paste and fly ash blended paste after 10 days of curing [105]. It can be seen that alkali concentration decreased considerably with the addition of fly ash. It was shown that inclusion of fly ash engaged the alkali ion from pore solution by providing free silicate surface that reduced the concentration of alkali ion. Although fly ash may contain a significant amount of alkali, some fly ash does not contribute alkali at all and others may provide a small proportion at a very slow rate $[105,106]$. Nixon \& Page [106] suggested that class F fly ash did not add alkali to the pore solution.

Secondly, fly ash consumes alkali from the pore solution by the pozzolanic reaction. As a result, the alkalinity of the pore solution is reduced significantly. Canham et al. [107] pointed out that pozzolanic CSH gel confined the alkali from pore solution, thus minimised the alkalinity of the pore solution. Besides, Hong and Glasser [82] stated that the alkali binding capacity primarily depends on the calcium to silica $(\mathrm{C} / \mathrm{S})$ ratio of the $\mathrm{CSH}$ gel. Fig. 12 shows the relationship between the $\mathrm{C} / \mathrm{S}$ ratio of $\mathrm{CSH}$ gel and the related alkali ( $\mathrm{Na}$ and $\mathrm{K}$ ) binding capacity [82]. It can be seen that low $\mathrm{C} / \mathrm{S}$ has higher alkali binding capacity as compared to high $\mathrm{C} / \mathrm{S}$ ratio. The authors concluded that $\mathrm{CSH}$ gel with low $\mathrm{C} / \mathrm{S}$ leads to form acidic silanol $(\mathrm{Si}-\mathrm{OH})$ groups, which is neutralised by the reaction of the alkalis $(\mathrm{NaOH}$ or $\mathrm{KOH})$. However, Detwiler [108] argued that it may not be possible to mitigate ASR expansion of highly reactive 
aggregates by fly ash, as there may not be enough time for the pozzolanic reaction to initiate and reduce the alkalinity of the pore solution.

Finally, fly ash reduces the calcium $(\mathrm{Ca})$ concentration of pore solution. At the very beginning, Chatterji [85] investigated the role of portlandite in ASR and offered a $\mathrm{CaCl}_{2}$ solution to leach out portlandite successfully from concrete to reduce ASR expansion. It was recommended to use a SCM to reduce the portlandite of concrete as an ASR mitigation technique. Then, Wang \& Gillott [86] explained that the presence of portlandite increased the alkalinity of pore solution by releasing hydroxyl ions. An experimental program carried out by Bleszynski \& Thomas [109] compared the effect of lime $\left(\mathrm{Ca}(\mathrm{OH})_{2}\right)$ on ASR expansion of OPC and fly ash blended concrete. The expansion results after 24 days obtained from the study are plotted in Fig. 13. It can be seen that both OPC and fly ash blended concrete slowed down expansion when $\mathrm{Ca}(\mathrm{OH})_{2}$ was added. The authors concluded that the presence of calcium in mixture creates a high calcium reaction rim, which acts as a semi-permeable membrane. This reaction rim allows the penetration of alkali hydroxides into the silica particle but prevents the circulation of the aqueous alkali-silica from the silica particle to pore solution [109]. However, the expansion was minimised when fly ash was added.

Therefore, pore solution chemistry undoubtedly plays the most significant role to initiate ASR expansion. However, the addition of fly ash changes the scenario of the pore solution chemistry by binding alkali and removing free calcium. As a result, fly ash can reduce the ASR expansion of concrete and mortar.

\subsection{Alteration of ASR gel}

It has been shown in some research that ASR gel is produced in mortar and concrete containing fly ash without considerable expansion. This is because fly ash can change the ASR gel properties by reducing the viscosity, swelling capacity and swelling pressure [74, 109, 110]. Struble and Diamond [111] investigated the swelling properties of sodium silicate and sodium calcium silicate gels to identify the basic mechanism of ASR expansion in concrete with sodium hydroxide as a source of potential alkali. It was found that sodium silicate (Na-Si) gel was in a fluid state, whereas sodium calcium silica gel was in a solid state. Bleszynski \& Thomas [109] found that alkali-silica gel was formed in low calcium and high alkali fly ash concretes. This gel acted as a fluid and was diffused in the cement paste. On the other hand, for conventional concrete, alkali present in this gel was replaced by calcium and produced a viscous product, which swelled in contact with water. Later, Ichikawa [74] concluded that the alkali silicate is fluid in nature and is also able to diffuse in pores of the paste; however, the presence of calcium $\left(\mathrm{Ca}^{++}\right)$replaces alkali from the alkali silicates to create solid calcium alkali silicates, which is expansive in nature. On the other hand, the inclusion of fly ash reduces the calcium content in the mix. Therefore, less amount of calcium alkali silicate is produced. Hence, the deleterious expansion due to ASR is mitigated. Bonakdar et al. [110] suggested that fly ash specimens contained fibrous platelets of $\mathrm{Ca}-\mathrm{Na}-\mathrm{Si}-\mathrm{O}$ groups and it formed a nonexpansive dense network of scattered distribution. Recently, Gholizadeh-Vayghan and Rajabipour [112] conducted an experiment on synthetic ASR gel of different chemical 
compositions. The authors found that swelling pressure and water absorption capacity of ASR gel increased with the increment of $\mathrm{Na} / \mathrm{Si}$ and $\mathrm{K} / \mathrm{Si}$ ratios. Furthermore, in another study by Vayghan et al. [51] showed that ASR gel with $\mathrm{Ca} / \mathrm{Si}=0.2$ and $\mathrm{Na} / \mathrm{Si}=0.85$ exhibited the highest expansion and swelling pressure. The measured $\mathrm{pH}$ of the synthetic gels with respect to calcium and sodium content at different time intervals are presented in Fig. 14. In this figure, a gel with low $\mathrm{Ca} / \mathrm{Si}$ and $\mathrm{Na} / \mathrm{Si}$ is denoted as $\mathrm{C}-\mathrm{N}-$, high $\mathrm{Ca} / \mathrm{Si}$ and $\mathrm{Na} / \mathrm{Si}$ is denoted as $\mathrm{C}+\mathrm{N}+$, low $\mathrm{Ca} / \mathrm{Si}$ and high $\mathrm{Na} / \mathrm{Si}$ is denoted as $\mathrm{C}-\mathrm{N}+$, and high $\mathrm{Ca} / \mathrm{Si}$ and low $\mathrm{Na} / \mathrm{Si}$ is denoted as $\mathrm{C}+\mathrm{N}-$. As seen in Fig. 14, C-N+ and $\mathrm{C}+\mathrm{N}-$ do not have a major influence on the pore solution $\mathrm{pH}$. However, $\mathrm{C}+\mathrm{N}+$ significantly increased the pore solution $\mathrm{pH}$. Therefore, the addition of fly ash as a SCM is an effective solution to reduce the alkali-silica ratio as well as calcium silica ratio in ASR gel.

In contrast, Powers \& Steinour [113] believed that expansion occurs due to swelling of alkali-silica (Na-Si) gel and a non-expansive lime-alkali-silica gel is generated in presence of sufficient lime. Similarly, Monteiro et al. [114] stated that the presence of higher lime/alkali ratio in alkali-silica gel reduces the expansion of the gel. Helmuth et al. [115] also observed the similar trend and reported that the presence of excessive alkali can reduce expansion due to the spontaneous reaction from diffusion of silica to the unconfined sites. Thus high $\mathrm{Na} / \mathrm{Si}$ ratio reduces the gel viscosity and swelling pressure.

Therefore, the presence of fly ash modifies the alkali-silica gel properties, which leads to the reduction of expansion. However, contradictory opinions are found in literature about the chemical composition of ASR gel and its swelling pressure. Moreover, further experimental works can be conducted to evaluate the chemical composition of ASR gel and its swelling pressure comprehensively.

\subsection{Reduction of porosity}

The porosity of concrete plays a vital role in expansion due to ASR. Usually, high porosity of concrete allows moisture from the surrounding to penetrate and trigger ASR. According to the study by Bulteel et al. [116], at first, alkali diffused in the pores between aggregate and the binder matrix and then initiated the aggregate dissolution, and finally started ASR. Similarly, Multon et al. [117] pointed out that ASR gel penetrates through the voids between the aggregate and cement paste. Later, this gel imparts swelling pressure and causes expansion and cracking. Haha et al. [118] also found that highly porous aggregates suffered from greater expansion as compared to the aggregates with lower porosity. Similarly, Shah and Ahmad [119], and Steffens et al. [120] showed that lower porosity increases the ASR resistance of e concrete structures. Furthermore, Moser et al. [57] investigated the relationship between the hydraulic permeability of concrete and ASR expansion. According to the findings reported by the authors, SCM reduced the permeability of concrete that resulted in the reduction of water absorption and expansion of the ASR gel. Fly ash concrete has lower permeability due to two main reasons: firstly, reduction of the transition zone thickness between surrounding aggregates and cement matrix; and secondly, fly ash reduces the pore size of the binder matrix by pozzolanic reaction product and filling effect of the fine unreacted particles [121, 122]. 
Thus, low permeability of fly ash samples reduces alkali diffusion from the surroundings. Furthermore, the presence of fewer pores in cement paste mitigates the alkali-silica reaction as well as accumulation of alkali-silica gel. As a result, fly ash specimens exhibit less expansion. In contrast, Pandey \& Sharma [123] found that use of fly ash as a partial replacement of cement increased the porosity of the mortar samples at the initial stages of curing. Similarly, Chindaprasirt and Jaturapitakkul [124] pointed out that fly ash blended cement paste showed higher porosity when compared to Portland cement paste. The higher porosity of the samples was because of less reaction product or reduced rate of hydration at the early ages due to cement replacement by fly ash. Therefore fly ash concrete exhibited higher porosity at early ages as compared to concrete without fly ash [123, 124].

Although the use of fly ash may show higher porosity at the early age of curing, it can reduce the internal pores and prevent the ASR gel accumulation around the aggregates at the later ages. Furthermore, fly ash reduces permeability by pozzolanic reaction and filler effect that can eventually reduce the alkali attack from the surrounding environment.

\section{Test methods and their limitations}

AMBT and CPT have been adopted in different standards and used by researchers for decades to identify potentially reactive aggregates and evaluate the effectiveness of supplementary cementing materials to mitigate ASR. Yet, in some cases, these two test methods have been unsuccessful to predict the deleterious expansion due to ASR. Shi et al. [125] hold the view that the exposure period of 16 days for AMBT is not sufficient for slowly reactive aggregates. Their experimental study showed expansion of specimens within the allowable limit for 16 days of the test with much higher expansions thereafter. Fernández-Jiménez et al. [126] showed that formation of zeolite can lead to a rapid expansion after initial low values during the first 16 days of the test. Therefore, Palacios \& Puertas [127] recommended to extend the test for up to 6 months. Furthermore, this test condition requires submerging the samples at $80{ }^{\circ} \mathrm{C}$ in $1 \mathrm{M}$ Sodium hydroxide $(\mathrm{NaOH})$ which is very harsh as compared to field condition. Therefore, this test often exhibited misleading results and identified aggregates as reactive while they showed satisfactory field performance [128]. As a result, CPT has been adopted in addition to AMBT to identify the reactive aggregates which exhibits a more realistic concrete exposure condition. During this testing method, samples are exposed at $38{ }^{\circ} \mathrm{C}$ at $95 \% \mathrm{RH}$ for a period of 1 year [61]. In addition, ASTM C1293 [61] suggests that if an aggregate exhibited expansion exceeding the allowable limit in AMBT but the expansion was lower than the allowable limit in CPT, the aggregate can be used in concrete constructions. However, this test requires one year, which is considered to be long to identify reactive aggregates [125]. In addition, the test specimens suffer from significant alkali leaching during the CPT [129, 130, 131]. For this reason, some researchers suggested to conduct the test for two years in order to have a better understanding of the amount of SCM's required to mitigate ASR expansion [132, 133, 134]. Even two years of testing of concrete prisms has shown not enough reliability of results in some cases. Rajabipour et al. [72] pointed out that concrete using high-alkali SCM's exhibited expansion within the allowable limit $(\leq 0.04 \%)$ after two years of testing, yet exhibited deleterious expansion after 8 to 10 years. Ideker et al. [84] conducted an experimental program 
on concrete using high-alkali SCM's and reactive aggregates which was tested for more than 10 years. It is reported that the concrete samples started significant cracking only after 10 years due to a steady release of alkali from the SCM's. Furthermore, to overcome the time lag of the reaction, researchers are currently evaluating the effectiveness of CPT [135-137]. During CPT, the samples are exposed to a temperature of $60{ }^{\circ} \mathrm{C}$ for 6 months [137]. However, Ideker et al. [135] found that accelerated testing leads to misleading prediction of aggregate reactivity. Similarly, Islam \& Akhtar [136] pointed out that accelerated concrete prism test is unreliable to measure the SCM's requirement to mitigate ASR. Considering the limitations of current test methods establishment of the alternative test method to determine the safe percentage of SCM's in concrete to mitigate ASR is a matter of great importance.

\section{Optimum percentage of fly ash to mitigate ASR}

It is known that both class $\mathrm{C}$ and class F fly ash as a SCM has the ability to mitigate ASR in concrete. However, use of an excessive volume of fly ash as cement replacement can significantly reduce the early age strength of concrete which can be a major concern for its commercial application. For example, Supit et al. [139] showed that use of class F fly ash as a SCM replacing $40 \%$ OPC in concrete, the 7-day compressive strength was only $61 \%$ of its 28 day strength, as compared to $85 \%$ for the control concrete. On the other hand, optimising the quantity of fly ash can lead to a noticeable early age strength development. For instance, Saha and Sarker [63] found that for 30\% cement replacement by a class F fly ash, the 7-day compressive strength was $78 \%$ compared of its 28 -day compressive strength. Therefore, it is essential to adopt the optimum amount of fly ash which will control the ASR without compromising much of the early age strength. According to recent studies $30 \%$ class F fly ash is optimum to reduce the ASR expansion within the allowable limit in both AMBT and CPT [140-145]. In addition, researchers recommend using at least $50 \%$ class $\mathrm{C}$ fly ash to mitigate deleterious ASR [142-147]. Furthermore, a recent numerical modelling on ASR by Vayghan et al. [147] recommended using $30 \%$ class $\mathrm{F}$ fly ash or $50 \%$ class $\mathrm{C}$ fly ash to mitigate ASR. Besides, replacing cement by fly ash in concrete reduce the rate of hydration which lead to the low early age strength $[63,139]$. In order to overcome the issue of low early-age strength due to the use of fly ash, researchers adopted different techniques, such as addition of ultra-fine fly ash or nano-silica blended with fly ash. For instance, Supit et al. [139] experimentally showed that addition of ultra-fine fly ash blended with conventional fly ash can accelerate the heat of hydration and the concrete samples exhibited high early age strength development. According to the experimental findings, after 7 days of curing period, the samples containing $8 \%$ ultrafine fly ash with $32 \%$ regular fly ash gained $75 \%$ of its 28 -day compressive strength. Concrete with $40 \%$ fly ash exhibited only $61 \%$ strength at 7 days of curing compared to its 28 day strength. Besides, the application of this blend (ultrafine fly ash and fly ash) to mitigate ASR has not been investigated by researchers. Thus, this ternary blend of ultrafine fly ash, fly ash and OPC can be considered for future research works to evaluate ASR mitigation. Furthermore, Shaikh et al. [149] showed that application of nano-silica blended with fly ash and cement can improve the early age compressive strength of the concrete up to $7 \%$ and suggested that $2 \%$ nano-silica as the optimum quantity. Similarly, Supit \& Shaikh [150] pointed out that addition of $2 \%$ nano silica blended with fly ash and OPC increased the density of the microstructure and reduced 
the pore size. Furthermore, addition of nano-silica accelerate the pozzolanic reaction and thus exhibits higher strength development as compared to use of fly ash without nano-silica [150]. Besides, researchers also evaluated the ASR mitigation measure of nano-silica blended with fly ash. Zeidan and Said $[142,151]$ showed that nano-silica (3\%) blended with fly ash (29\%) and cement $(68 \%)$ was able to reduce the expansion within allowable limit. Similarly, Mukhopadhyay and Liu [152] showed that fly ash and nano-silica blends can reduce the expansion due to ASR. In addition, experimental data showed that addition of nano-silica can reduce the OPC replacement level by fly ash to mitigate ASR. According to the test results $35 \%$ fly ash was essential to mitigate the ASR but samples containing 1\% nano-silica blended with only $25 \%$ fly ash exhibited satisfactory performance regarding ASR expansion [152]. However, nano-silica is not readily available around the world and can increase the concrete production cost $[153,154]$. Therefore, further investigation can be carried out regarding alternative approach to find a suitable quantity of fly ash and without compensating the early age strength of concrete.

\section{Effectiveness of fly ash over other SCMs to mitigate ASR}

Researchers have studied different SCMs apart from fly ash to mitigate ASR in concrete, such as slag, metakaolin and glass powder. All the SCMs were effective to reduce ASR because they consist of high amount of amorphous silica which consume portlandite and reduce the alkalinity of pore solution. However, the dosage of SCMs can be significantly different depending on the chemical composition [155-159]. It is suggested that more than 50\% cement replacement by GGBFS is necessary to control ASR [33, 134, 155]. GGBFS generally consists of $20-30 \%$ silica content as compared to $50-70 \%$ in class $\mathrm{F}$ fly ash. Therefore higher replacement of OPC is required by GGBFS to mitigate ASR [33]. Boháč et al. [160] pointed out that addition of $50 \%$ GGBFS significantly reduce the heat of hydration compared to $100 \%$ OPC. Specimens with fly ash showed very low early age compressive strength [161]. Similarly, Ustabaş and Kaya [162] showed that samples with 50\% slag has SCM has a significantly low compressive strength of $18 \mathrm{MPa}$ whereas OPC samples had a strength of $40 \mathrm{MPa}$ after 7 days of curing. The experimental results also point out that $25 \%$ fly ash blends had a compressive strength around $30 \mathrm{MPa}$. Thus, fly ash has the clear advantage over slag as lower replacement of fly ash can be adopted to mitigate ASR without significant reduction of early age strength. In addition, slag generally need grinding before use as a SCM [163]. Fly ash can be used without any further processing from its source which makes it a more economical option compared to slag [164-166]. Furthermore, metakaolin has been another popular choice among researchers to mitigate ASR. Ramlochan et al. [167] pointed out that $20 \%$ dosage of highly reactive metakaolin (HRM) was sufficient to control ASR in both AMBT and CPT for two different types of reactive aggregates such as Spratt and Sudbury. Similarly, Aquino [23] pointed out that, HRM reduce the portlandite content from pore solution thus control ASR. On the contrary, Lee et al [168] pointed out that $20 \%$ dosage of metakaolin was unable to reduce the ASR expansion of mortar bars using recycled glass aggregate, however, $20 \%$ replacement of OPC by fly ash was successful to reduce the expansion within the allowable limit. Furthermore, waste glass powder has got the attention of researchers as a SCM due to its pozzolanic activity. The recent findings suggested that it improve the durability of concrete 
$[169,170]$. This leads to its application as an ASR mitigating measure [157, 158, 171-173]. Zheng [157] pointed out that replacement of cement by $30 \%$ waste glass powder successfully mitigate ASR expansion. The effectiveness of glass powder to mitigate ASR was attributed to two primary reasons. First, glass powder consumes portlandite by pozzolanic reaction. Second, it releases alumina in pore solution which minimized the dissolution of reactive aggregates [157]. Similarly, Afshinnia \& Rangaraju [158] showed that application of 30\% glass power as SCM can control the ASR within the allowable limit. In addition, authors pointed out that fineness of glass powder as SCM plays a crucial role to prevent ASR. The experimental studies indicated that 17-micron glass particles as a SCM showed lower expansion compared to 70microns particles for an equal replacement ratio. Furthermore, Guo et al. [171] conducted AMBT for the samples using 30\% glass powder as a SCM and found that the expansion was within allowable limit and microstructure studies also indicated the absence of ASR gel in the samples. Even though glass powder was successful to mitigate ASR, for an equal dosage of fly ash and glass powder with similar reactive aggregates the fly ash found to be more effective [173]. In addition, the waste glass requires careful recycling process in order to make it suitable for replacing cement in concrete which can be costly [174]. Therefore, fly ash has a clear advantage over other SCMs considering an economical way to mitigate ASR as well as without excessive reduction of early age strength.

\section{Conclusions}

The following conclusions are drawn based on the extensive literature review on ASR mechanism in concrete and the contribution of fly ash:

1. ASR expansion is one of the most severe durability related issues for concrete structures. This expansion can be deleterious depending on its magnitude and may lead to significant cracking and strength loss of concrete. The presence of reactive silica in aggregate and high alkalinity of pore solution are the primary reasons for ASR. The process starts with the disintegration of the reactive silica by alkali attack from pore solution. This forms alkali silicate gel which absorbs moisture from the surroundings and generates swelling pressure in concrete.

2. Extensive research has been conducted to explore the effect of fly ash on ASR. Though there is some scientific debate among researchers, most research works clearly demonstrate the positive contribution of fly ash as an ASR mitigation method by the following mechanisms:

2.1 Use of class F fly ash as a partial replacement of cement is found to be more effective than class C fly ash in reducing ASR. Fly ash with higher percentages of silica and alumina and lower percentages of alkali and calcium oxides are found to be most effective in reducing ASR.

2.2. Fly ash prevents aggregate dissolution due to alkali attack by providing sacrificial amorphous silicate surface area. 
2.3. The addition of fly ash reduces the $\mathrm{pH}$ of pore solution by alkali binding and reducing free calcium ions.

2.4. Fly ash modifies the chemical composition of ASR gel and reduces its swelling properties so that the gel can move freely into the voids between aggregate and binder paste.

2.5. Fly ash reduces the porosity of binder matrix that offers resistance against alkali diffusion from the surroundings.

3. Thus, use of class F fly ash as a supplementary cementitious material is considered as an effective and efficient method of ASR mitigation of concrete utilising various reactive aggregates obtained from natural sources and industrial processes as by-products. Utilisation of these aggregates together with fly ash can make a significant contribution towards sustainable concrete production.

\section{Recommendations for the further research}

Based on the existing research gaps identified in the extensive review, the following recommendations are proposed for further research:

1. Identification of the degree of reactivity is the major drawback in ASR mitigation. The test methods are limited to identify the amount of aggregate dissolution taking place in this process. Therefore, further research on the development of a comprehensive test procedure to determine the degree reactivity of aggregates would be useful to better understand ASR.

2. Usually, fly ash consists of silica, alumina, calcium and alkali oxides. However, it is not clear yet how the alumina influences the ASR mitigation. Therefore, further study is needed in order to understand the role of alumina in ASR. This will help the manufacturing of low alkali cement for use with reactive aggregates.

3. There are some contradictory opinions among researchers about how the chemical composition of ASR gel influences its swelling properties. Further research is needed to enhance the knowledge on swelling behaviour of ASR gel.

4. Fly ash consists of noticeable amount of alkali, often higher than OPC. Therefore standard test needs to be developed to evaluate the long-term effect of this alkali contribution in ASR expansion.

5. It would be useful to have an analytical model based on chemical compositions of the ingredients for determination of the proportions of fly ash, cement and reactive aggregates in a concrete mix design with predicted ASR expansion within the allowable limit. 
6. Use of $30 \%$ class $\mathrm{F}$ fly ash as a SCM can be considered adequate to mitigate ASR of reactive aggregates. In contrast, at least $50 \%$ class $\mathrm{C}$ fly ash may be required for reduction of ASR expansion by the same level.

7. Further investigations on the improvement of the reliability of AMBT and CPT results would be useful to identify potential ASR of aggregates with more confidence.

\section{References}

[1] T.E. Stanton, Expansion of concrete through reaction between cement and aggregate, Proceedings of the American Society of Civil Engineers, 66 (10) (1940) 1781-811.

[2] T.E. Stanton, Studies of use of pozzolans for counteracting excessive concrete expansion resulting from reaction between aggregates and the alkalies in cement, In Symposium on Use of Pozzolanic Materials in Mortars and Concretes, ASTM International, 1950.

[3] W.F. Cole, C.J. Lancucki, M.J. Sandy, Products formed in an aged concrete, Cem. Concr. Res. 11(3) (1981) 443-454.

[4] K. Ono, Damaged concrete structures in Japan due to alkali silica reaction, Inter. J. Cem. Compos. Light. Concr. 10(4), (1988) 247-57.

[5] R. N. Swamy, Alkali-Silica Reaction in Concrete, Glasgow and London: Blackie and Son Ltd., (1992).

[6] Chiaramida, A. (2017). NRC presses nuke plant on concrete problem. http://www.seacoastonline.com/news/20171026/nrc-presses-nuke-plant-on-concreteproblem. (Updated on Oct 26, 2017).

[7] https://www.azobuild.com/news.aspx?newsID=21844. Scientists Investigate AlkaliSilica Reaction in Concrete in Mactaquac Dam, Canada (Published on September 15, 2017).

[8] M. Berra, T. Mangialardi, A.E. Paolini, R. Turriziani, Critical evaluation of accelerated test methods for detecting the alkali-reactivity of aggregates, Adv. Cem. Res. 4(13) (1991) 29-37.

[9] M. Davraz, L. Gündüz, Reduction of alkali silica reaction risk in concrete by natural (micronised) amorphous silica, Constr. Build. Mater. 22(6) (2008) 1093-1099.

[10] M.A. Bérubé, J. Duchesne, J.F. Dorion, M. Rivest, Laboratory assessment of alkali contribution by aggregates to concrete and application to concrete structures affected by alkali-silica reactivity, Cem. Concr. Res. 32(8) (2002) 1215-1227.

[11] M.-A Bérubé, M Pigeon, N Dupont, J Frenette, M Langlois, Expansion Test Methods for Mass Concrete Exposed to Alkali Aggregate Reaction, Canadian Electrical Association, Montréal, 1992.

[12] J.H.P. Van Aardt, S. Visser, Calcium hydroxide attack on feldspars and clays: possible relevance to cement-aggregate reactions, Cem. Concr. Res. 7(6) (1977) 643-648. 
[13] P. E. Grattan-Bellew, L. D. Mitchell, J. Margeson, D. Min, Is alkali-carbonate reaction just a variant of alkali-silica reaction $\mathrm{ACR}=\mathrm{ASR}$, Cem. Concr. Res. 40(4) (2010) 556-562.

[14] İ. B. Topçu, A. R. Boğa, T. Bilir, Alkali-silica reactions of mortars produced by using waste glass as fine aggregate and admixtures such as fly ash and $\mathrm{Li}_{2} \mathrm{CO}_{3}$, Waste. Manag. 28(5) (2008) 878-884.

[15] M.C.G. Juenger, C.P. Ostertag, Alkali-silica reactivity of large silica fume-derived particles, Cem. Concr. Res. 34(8) (2004) 1389-1402.

[16] T. Chappex, K. Scrivener, Alkali fixation of C-S-H in blended cement pastes and its relation to alkali silica reaction, Cem. Concr. Res. 42(8) (2012) 1049-1054.

[17] A. K Saha, P. K. Sarker, Expansion due to alkali-silica reaction of ferronickel slag fine aggregate in OPC and blended cement mortars, Constr. Build. Mater. 123 (2016) 135142.

[18] M.D. Thomas, K.J. Folliard, B. Fournier, P. Rivard, T. Drimalas, Methods for Evaluating and Treating ASR-Affected Structures: Results of Field Application and Demonstration Projects-Volume I: Summary of Findings and Recommendations (No. FHWA-HIF-14-0002) (2013).

[19] M.H. Shehata, M.D. Thomas, Use of ternary blends containing silica fume and fly ash to suppress expansion due to alkali-silica reaction in concrete, Cem. Concr. Res. 32(3) (2002) 341-349.

[20] S. Diamond, Effects of Microsilica (Silica Fume) on Pore-Solution Chemistry of Cement Pastes, J. Ame. Ceram. Socie. 66(5) (1983).

[21] C.L. Page, Ø. Vennesland, Pore solution composition and chloride binding capacity of silica-fume cement pastes, Matériaux et Construction. 16(1) (1983) 19-25.

[22] S. Diamond, Alkali silica reactions-some paradoxes, Cem. Concr. Compos. 19(5) (1997) 391-401.

[23] W. Aquino, D.A. Lange, J. Olek, The influence of metakaolin and silica fume on the chemistry of alkali-silica reaction products, Cem. Concr. Compos. 23(6) (2001) 485493.

[24] B. Fournier, P.C. Nkinamubanzi, R. Chevrier, Comparative field and laboratory investigations on the use of supplementary cementing materials to control alkali-silica reaction in concrete, In Proceeding 12th International Conference on AAR in Concrete. Beijing, China (2004).

[25] R.E. Oberholster, Alkali-aggregate reaction in South Africa. Some recent developments in research, In Proceedings of the 8th International Conference on Alkali-Aggregate Reaction (Eds. K. Okada, S. Nishibayashi and M. Kawamura), Kyoto, (1989) 77-82.

[26] G.J. Osborne, Durability of Portland blast-furnace slag cement concrete, Cem. Concr. Com. 21(1), (1999) 11-21.

[27] D.M. Roy, 1982, Hydration, structure, and properties of blast furnace slag cements, mortars, and concrete, ACI Mater. J. 79(6) (1982) 444-457.

[28] R. Bleszynski, R.D. Hooton, M.D. Thomas, C. A. Rogers, Durability of ternary blend concrete with silica fume and blast-furnace slag: laboratory and outdoor exposure site studies, ACI Mater. J. 99(5) (2002) 499-508. 
[29] H.W. Song, V. Saraswathy, Studies on the corrosion resistance of reinforced steel in concrete with ground granulated blast-furnace slag an overview, J. Hazar Mater. 138(2) (2006) 226-233.

[30] S.E. Hussain, Effect of microsilica and blast furnace slag on pore solution composition and alkali-silica reaction, Cem. Concr. Com. 13(3) (1991) 219-225.

[31] Y. C. Choi, S. Choi, Alkali-silica reactivity of cementitious materials using ferro-nickel slag fine aggregates produced in different cooling conditions, Constr. Build. Mater. 99 (2015) 279-287.

[32] L.J. Malvar, G.D. Cline, D.F. Burke, R. Rollings, T.W. Sherman, J.L. Greene, Alkalisilica reaction mitigation: state of the art and recommendations, Mater. J. 99(5) (2002) 480-489.

[33] M. Thomas, The effect of supplementary cementing materials on alkali-silica reaction: A review, Cem. Concr. Res. 41(12) (2011) 1224-1231.

[34] J. Duchesne, M.A. Bérubé, The effectiveness of supplementary cementing materials in suppressing expansion due to ASR: another look at the reaction mechanisms part 2: pore solution chemistry, Cem. Concr. Res. 24(2) (1994) 221-230.

[35] S.J. Barnett, M.N. Soutsos, S.G. Millard, J.H. Bungey, Strength development of mortars containing ground granulated blast-furnace slag: Effect of curing temperature and determination of apparent activation energies, Cem. Concr. Res. 36(3) (2006) 434440.

[36] G. Li, X. Zhao, Properties of concrete incorporating fly ash and ground granulated blast-furnace slag, Cem. Concr. Compos. 25(3) (2003) 293-299.

[37] V.M. Malhotra, High-performance high-volume fly ash concrete, ACI Mater. J. 24(7) (2002) 30-34.

[38] A. Bilodeau, V.M. Malhotra, High-volume fly ash system: the concrete solution for sustainable development, In CANMET/ACI. Séminaire international (2000).

[39] A. Oner, S. Akyuz, R. Yildiz, An experimental study on strength development of concrete containing fly ash and optimum usage of fly ash in concrete, Cem. Concr. Res. 35(6) (2005) 1165-1171.

[40] M. Thomas, A. Dunster, P. Nixon, B. Blackwell, Effect of fly ash on the expansion of concrete due to alkali-silica reaction-Exposure site studies, Cem. Concr. Comp. 33(3) (2011) 359-367.

[41] G. Li, Properties of high-volume fly ash concrete incorporating nano-SiO $2, \mathrm{Cem}$. Concr. Res. 34(6) (2004) 1043-1049.

[42] B. Godart, M. de Rooij, J.G.M. Wood, Guide to Diagnosis and Appraisal of AAR Damage to Concrete in Structures, Part 1 Diagnosis (AAR 6.1), RILEM State-of-theArt Reports, 12 (2013).

[43] F.P. Glasser, Chemistry of the alkali aggregate reaction, in: R.N. Swamy (Ed.), The Alkali-Silica Reaction in Concrete, Blackie, Glasgow and London, and Van NostrandReinhold, New York, 1992, pp. 30-53.

[44] R. N. Swamy, The alkali-silica reaction in concrete, CRC Press (2002).

[45] T. Ichikawa, M. Miura, Modified model of alkali-silica reaction, Cem. Concr. Res. 37(9), (2007) 1291-1297. 
[46] Z. P. Bažant, A. Steffens, Mathematical model for kinetics of alkali-silica reaction in concrete, Cem. Concr. Res. 30(3) (2000) 419-428.

[47] R. Dron, F. Brivot, Thermodynamic and kinetic approach to the alkali-silica reaction. Part 1: Concepts, Cem. Concr. Res. 22(5) (1992) 941-948.

[48] R. Dron, F. Brivot, Thermodynamic and kinetic approach to the alkali-silica reaction, Part 2: Experiment. Cem. Concr. Res. 23(1) (1993) 93-103.

[49] S. Diamond, Chemistry and other characteristics of ASR gels. In Proceedings of the 11th International Conference on Alkali-Aggregate Reaction in Concrete, Quebec City, Canada, 2000, pp. 40.

[50] N. Thaulow, U.H. Jakobsen, B. Clark, Composition of alkali silica gel and ettringite in concrete railroad ties: SEM-EDX and X-ray diffraction analyses, Cem. Concr. Res. 26(2) (1996) 309-318.

[51] A.G. Vayghan, F. Rajabipour, J.L. Rosenberger, Composition-rheology relationships in alkali-silica reaction gels and the impact on the Gel's deleterious behavior, Cem. Concr. Res. 83 (2016) 45-56.

[52] B. Cotterell, J. Kamminga, Mechanics of pre-industrial technology: An introduction to the mechanics of ancient and traditional material culture, Cambridge University Press. (1992).

[53] V. Ducman, A. Mladenovič, J.S. Šuput, Lightweight aggregate based on waste glass and its alkali-silica reactivity, Cem. Concr. Res. 32(2) (2002) 223-226.

[54] F. Rajabipour, H. Maraghechi, G. Fischer, Investigating the alkali-silica reaction of recycled glass aggregates in concrete materials, J. Mater. Civ. Eng. 22(12) 20101201 1208.

[55] M.H. Shehata, M.D. Thomas, The effect of fly ash composition on the expansion of concrete due to alkali-silica reaction, Cem. Concr. Res. 30(7) (2000) 1063-1072.

[56] I. García-Lodeiro, A. Palomo, A. Fernández-Jiménez, Alkali-aggregate reaction in activated fly ash systems, Cem. Concr. Res. 37(2) (2007) 175-183.

[57] R.D. Moser, A.R. Jayapalan, V.Y. Garas, K.E. Kurtis, Assessment of binary and ternary blends of metakaolin and Class $\mathrm{C}$ fly ash for alkali-silica reaction mitigation in concrete, Cem. Concr. Res. 40(12) (2010) 1664-1672.

[58] S.M. Shafaatian, A. Akhavan, H.Maraghechi, F. Rajabipour, How does fly ash mitigate alkali-silica reaction (ASR) in accelerated mortar bar test (ASTM C1567), Cem. Concr. Compos. 37 (2013) 143-153.

[59] ASTM C1260 - Standard Test Method for Potential Alkali Reactivity of Aggregates (Mortar-Bar Method). American Society for Testing and Materials, West Conshohocken, PA (2001).

[60] ASTM C1567 - Standard Test Method for Determining the Potential Alkali-Silica Reactivity of Combination of Cementitious Materials and Aggregates (Accelerated Mortar Bar Method). American Society for Testing and Materials, West Conshohocken, PA (2008).

[61] ASTM C1293 - Standard Test Method for Determination of Length Change of Concrete Due to Alkali-Silica Reaction. American Society for Testing and Materials, West Conshohocken, PA (2001) 
[62] https://en.wikipedia.org/wiki/Obsidian\#/media/File:Lipari-Obsidienne_(5).jpg

[63] A.K. Saha, P.K. Sarker, Sustainable use of ferronickel slag fine aggregate and fly ash in structural concrete: Mechanical properties and leaching study, J. Clean. Produc. 162, 2017, 438-448.

[64] http://www.pressherald.com/2016/03/13/glass-jars-shatter-recycling-expectations/

[65] G.M. Crisci, M. Ricq-De Bouard, U. Lanzaframe, A.M. De Francesco, I. Nouvelle méthode d'analyse et provenance de l'ensemble des obsidiennes néolithiques du Midi de la France, Gallia préhistoire, 36(1), (1994) 299-309.

[66] H. Funk, The origin of authigenic quartz in the Helvetic Siliceous Limestone (Helvetischer Kieselkalk), Switzerland, Sedimentology, 22(2), (1975) 299-306.

[67] Y. Monnin, P. Dégrugilliers, D. Bulteel, E. Garcia-Diaz, Petrography study of two siliceous limestones submitted to alkali-silica reaction, Cem Concr. Res. 36(8) (2006) 1460-1466.

[68] Z. Li, R.J. Thomas, D. Lazama, S. Peethamparan, Alkali Silica Reaction (ASR) in Cement Free Alkali Activated Sustainable Concrete, Project Brief, University Transportation Research Center (UTRC), Clarkson University, 2016.

[69] N.P. Hasparyk, J.M.M. Paulo, C. Helena, Effect of silica fume and rice husk ash on alkali-silica reaction, ACI Mater. J. 97(4), (2000) 486-492.

[70] E. Brouard, Potentially reactive aggregates with a pessimum effect, pessimum effect mechanisms, review of PRP qualification tests and conditions of use of these aggregates, In Proceedings of the 14th International conference on alkali aggregate reaction, Austin, Texas, USA, 2012, pp. 10.

[71] S. Poyet, A. Sellier, B. Capra, G. Foray, J.M. Torrenti, H. Cognon, E. Bourdarot, Chemical modelling of Alkali Silica reaction: Influence of the reactive aggregate size distribution, Mater. Struct. 40(2) (2007) 229-239.

[72] F. Rajabipour, E. Giannini, C. Dunant, J.H. Ideker, M.D. Thomas, Alkali-silica reaction: current understanding of the reaction mechanisms and the knowledge gaps, Cem. Concr. Res. 76 (2015) 130-146.

[73] H. Maraghechi, G. Fischer, F. Rajabipour, The role of residual cracks on alkali silica reactivity of recycled glass aggregates, Cem. Concr. Compos. 34(1) (2012) 41-47.

[74] T. Ichikawa, Alkali-silica reaction, pessimum effects and pozzolanic effect, Cem. Concr. Res. 39(8) (2009) 716-726.

[75] D. Lu, X. Zhou, Z. Xu, X. Lan, M. Tang, B. Fournier, Evaluation of laboratory test method for determining the potential alkali contribution from aggregate and the ASR safety of the Three-Gorges dam concrete, Cem. Concr. Res 36(6) (2006) 1157-1165.

[76] F. Locati, S. Marfil, E. Baldo, Effect of ductile deformation of quartz-bearing rocks on the alkali-silica reaction, Eng. Geo. 116(1) (2010) 117-128.

[77] P.E. Grattan-Bellew, Laboratory evaluation of alkali-silica reaction in concrete from Saunders Generating Station. ACI Mater. J. 92(2) (1995).1-9.

[78] R. Goguel, Alkali release by volcanic aggregates in concrete, Cem. Concr. Res. 25(4) (1995) 841-852. 
[79] H. Chen, J.A. Soles, V.M. Malhotra, Investigations of supplementary cementing materials for reducing alkali-aggregate reactions, Cem. Concr. Compos. 15(1-2) (1993) 75-84.

[80] M.H. Shehata, M.D. Thomas, Alkali release characteristics of blended cements, Cem. Concr. Res. 36(6) (2006) 1166-1175.

[81] M.S.Y. Bhatty, N.R. Greening, Interaction of alkalies with hydrating and hydrated calcium silicates, In Proceedings of the Fourth International Conference on the Effects of Alkalis in Cement and Concrete, Purdue, 1978, pp. 87-112.

[82] S.Y. Hong, F.P. Glasser, Alkali binding in cement pastes: Part I. The CSH phase, Cem. Concr. Res. 29(12) (1999) 1893-1903.

[83] H. Uchikawa, S. Uchida, S. Hanehara, Relationship between Structure and Penetrability of $\mathrm{Na}$ Ion in Hardened Blended Cement Paste, Mortar and Concrete, J. Res. Onoda Cem. Co. 41(121) (1989) 19-32.

[84] J.H. Ideker, T. Drimalas, A.F. Bentivegna, K.J. Folliard, B. Fournier, M.D.A. Thomas, A.C. Rogers, The Importance of Outdoor Exposure Site Testing, In 12th International Conference on Alkali-Aggregate Reactivity in Concrete, Austin, Texas, USA, 2012.

[85] S. Chatterji, The role of $\mathrm{Ca}(\mathrm{OH}) 2$ in the breakdown of portland cement concrete due to alkali-silica reaction, Cem. Concr. Res 9(2) (1979) 185-188.

[86] H. Wang, J.E. Gillott, Mechanism of alkali-silica reaction and the significance of calcium hydroxide, Cem. Concr. Res. 21(4) (1991). 647-654.

[87] M.D.A. Thomas, P.J. Nixon, K. Pettifer, V.M. Malhotra (Ed.) High-Performance High-Volume Fly Ash Concrete. In Proceedings of the 2nd International Conference on Durability of Concrete, ACI SP-126, Vol. II, American Concrete Institute, Detroit, (1991) pp. 919-940.

[88] T.C. Powers, H.H. Steinour, An interpretation of some published researches on the alkali-aggregate reaction Part 1-The chemical reactions and mechanism of expansion, In Journal Proceedings 51(2) (1955) 497-516.

[89] I. Fernandes, Composition of alkali-silica reaction products at different locations within concrete structures, Mater. Charac. 60(7) (2009) 655-668.

[90] A. Leemann, G. Le Saout, F. Winnefeld, D. Rentsch, B. Lothenbach, Alkali-silica reaction: the influence of calcium on silica dissolution and the formation of reaction products, J. Ame. Cera. Socie. 94(4) (2011) 1243-1249.

[91] ASTM C618 - Standard Specification for Coal Fly Ash and Raw or Calcined Natural Pozzolan for Use in Concrete. American Society for Testing and Materials, West Conshohocken, PA (2008).

[92] R.L. Carrasquillo, P.G. Snow, Effect of fly ash on alkali-aggregate reaction in concrete, Mater. J. 84(4) (1987) 299-305.

[93] E.R. Dunstan, The effect of fly ash on concrete alkali-aggregate reaction, Cem. Concr. Aggre. 3(2), (1981) 101-104.

[94] T.C. Esteves, R. Rajamma, D. Soares, A.S. Silva, V. M. Ferreira, J.A. Labrincha, Use of biomass fly ash for mitigation of alkali-silica reaction of cement mortars, Constr. Build. Mater. 26(1) (2012) 687-693. 
[95] C.S. Shon, S.L. Sarkar, D.G. Zollinger, Testing the effectiveness of Class C and Class F fly ash in controlling expansion due to alkali-silica reaction using modified ASTM C 1260 test method, J. Mater. Civil Eng. 16(1) (2004). 20-27.

[96] A.A. Awal, M. W. Hussin, The effectiveness of palm oil fuel ash in preventing expansion due to alkali-silica reaction, Cem. Concr. Compos. 19(4) (1997) 367-372.

[97] T. Ramlochan, M.D.A. Thomas, R. D. Hooton, The effect of pozzolans and slag on the expansion of mortars cured at elevated temperature: Part II: Microstructural and microchemical investigations, Cem. Concr. Res. 34(8) (2004) 1341-1356.

[98] S. Warner, J.H. Ideker, K. Schumacher, Alkali-silica reactivity and the role of alumina, In Proceedings of the 14th International Conference on Alkali-Aggregate Reactivity in Concrete (ICAAR), Austin, Texas. 2012.

[99] S.Y. Hong, F.P. Glasser, Alkali sorption by CSH and CASH gels: Part II. Role of alumina, Cem. Concr. Res. 32(7) (2002) 1101-1111.

[100] S. Shafaatian, Innovative methods to mitigate alkali-silica reaction in concrete materials containing recycled glass aggregates, (Ph.D. Dissertation), Pennsylvania State University, University Park, Pennsylvania, USA, 2012.

[101] T. Chappex, K.L. Scrivener, The influence of aluminium on the dissolution of amorphous silica and its relation to alkali silica reaction, Cem. Concr. Res. 42(12) (2012) 1645-1649.

[102] K.A. Schumacher, J.H. Ideker, New considerations in predicting mitigation of alkalisilica reaction based on fly ash chemistry, J. Mater. Civil Eng. 27(4) (2014) 04014144.

[103] J. Duchesne, M.A. Bérubé, Long-term effectiveness of supplementary cementing materials against alkali-silica reaction, Cem. Concr. Res. 31(7) (2001) 1057-1063.

[104] D. Hernández-Cruz, C.W. Hargis, J. Dominowski, M.J. Radler, P.J. Monteiro, Fiber reinforced mortar affected by alkali-silica reaction: A study by synchrotron microtomography, Cem. Concr. Compos. 68 (2016) 123-130.

[105] S. Diamond, Effects of two danish flyashes on alkali contents of pore solutions of cement-flyash pastes, Cem. Concr. Res. 11(3) (1981) 383-394.

[106] P.J. Nixon, C.L. Page, Pore solution chemistry and alkali aggregate reaction, ACI Mater. J. 100, (1987) 1833-1862.

[107] I. Canham, C.L. Page, P.J. Nixon, Aspects of the pore solution chemistry of blended cements related to the control of alkali silica reaction, Cem. Concr. Res. 17(5) (1987) 839-844.

[108] R. Detwiler, The Role of Fly Ash Composition in Reducing Alkali-Silica Reaction, Portland Cement Association, 1997.

[109] R.F. Bleszynski, M.D. Thomas, Microstructural studies of alkali-silica reaction in fly ash concrete immersed in alkaline solutions, Adv. Cem. Mater. 7(2) (1998) 66-78.

[110] A. Bonakdar, B. Mobasher, S.K. Dey, D.M. Roy, Correlation of reaction products and expansion potential in alkali-silica reaction for blended cement materials, ACI Mater. J. 107(4) (2010) 380-386

[111] L.J. Struble, S. Diamond, Swelling properties of synthetic alkali silica gels, J. Ame. Ceram. Socie. 64(11) (1981) 652-655. 
[112] A. Gholizadeh-Vayghan, F. Rajabipour, The influence of alkali-silica reaction (ASR) gel composition on its hydrophilic properties and free swelling in contact with water vapor, Cem. Concr. Res. 94 (2017) 49-58.

[113] T.C. Powers, H.H. Steinour, An Interpretation of Some Published Researches on the Alkali-Aggregate Reaction Part 2-A Hypothesis Concerning Safe and Unsafe Reactions with Reactive Silica in Concrete, In Journal Proceedings, 51(4) (1955) 785-812.

[114] P.J.M. Monteiro, K. Wang, G. Sposito, M.C. Dos Santos, W.P. de Andrade, Influence of mineral admixtures on the alkali-aggregate reaction, Cem. Concr. Res. 27(12) (1997) 1899-1909.

[115] R. Helmuth, D. Stark, S. Diamond, M. Moranville-Regourd, Alkali-silica reactivity: an overview of research, strategic highway research program report, SHRP-C-342, Washington DC U.S.A. 1993.

[116] D. Bulteel, E. Garcia-Diaz, C. Vernet, H. Zanni, Alkali-silica reaction: a method to quantify the reaction degree, Cem. Concr. Res. 32(8) (2002) 1199-1206.

[117] S. Multon, A. Sellier, M. Cyr, Chemo-mechanical modeling for prediction of alkali silica reaction (ASR) expansion, Cem. Concr. Res. 39(6) (2009) 490-500.

[118] M.B. Haha, E. Gallucci, A. Guidoum, K.L. Scrivener, Relation of expansion due to alkali silica reaction to the degree of reaction measured by SEM image analysis, Cem. Concr. Res. 37(8) (2007) 1206-1214.

[119] S.P. Shah, S.H. Ahmad, High performance concrete. Properties and applications, McGraw-Hill, 330 West, 42nd Street, New York, USA, 1994.

[120] A. Steffens, K. Li, O. Coussy, Aging approach to water effect on alkali-silica reaction degradation of structures, J. Eng. Mech. 129(1) (2003) 50-59.

[121] M. Kuroda, T. Watanabe, N. Terashi, Increase of bond strength at interfacial transition zone by the use of fly ash, Cem. Concr. Res. 30(2) (2000) 253-258.

[122] P.K. Mehta, P.J.M. Monteiro, Concrete: Microstructure, Properties and Materials, (3rd ed.), McGraw-Hill, New York, USA, 2006.

[123] S.P. Pandey, R.L. Sharma, The influence of mineral additives on the strength and porosity of OPC mortar, Cem. Concr. Res. 30(1) (2000) 19-23.

[124] P. Chindaprasirt, C. Jaturapitakkul, T. Sinsiri, Effect of fly ash fineness on compressive strength and pore size of blended cement paste, Cem. Concr. Compos. 27(4) (2005) 425-428.

[125] C. Shi, Z. Shi, X. Hu, R. Zhao, L. Chong, A review on alkali-aggregate reactions in alkali-activated mortars/concretes made with alkali-reactive aggregates, Mater. struct. 48(3) (2015) 621-628.

[126] A. Fernández-Jiménez, I. Garcia-Lodeiro, A. Palomo, Durability of alkali-activated fly ash cementitious materials, J. Mater. Sci. 42(9) (2007) 3055-3065.

[127] M. Palacios, F. Puertas, Effect of carbonation on alkali-activated slag paste, J. Ame. Cer. Soc. 89(10) (2006) 3211-3221.

[128] J.H. Ideker, A.F. Bentivegna, K.J. Folliard, M.C. Juenger, Do current laboratory test methods accurately predict alkali-silica reactivity?, ACI Mater. J. 109(4) (2012) 395402. 
[129] J. Lindgård, M.D. Thomas, E.J. Sellevold, B. Pedersen, Ö. Andiç-Çakır, H. Justnes, T.F. Rønning, Alkali-silica reaction (ASR) - performance testing: influence of specimen pre-treatment, exposure conditions and prism size on alkali leaching and prism expansion, Cem. Concr. Res. 53(2013) 68-90.

[130] J. Lindgård, Ö. Andiç-Çakır, I. Fernandes, T.F. Rønning, M.D. Thomas, Alkali-silica reactions (ASR): literature review on parameters influencing laboratory performance testing, Cem. Concr. Res. 42(2) (2012) 223-243.

[131] S. Multon, A. Sellier, Multi-scale analysis of alkali-silica reaction (ASR): Impact of alkali leaching on scale effects affecting expansion tests, Cem. Concr. Res. 81 (2016) 122-133.

[132] W. Touma, D.W. Fowler, R.L. Carrasquillo, Alkali-silica reaction in portland cement concrete: testing methods and mitigation alternatives. Research Report ICAR 301-1F, 2001. http://hdl.handle.net/2152/35397

[133] B. Fournier, M.A. Bérubé, K.J. Folliard, M.D.A. Thomas, Report on the Diagnosis, Prognosis, and Mitigation of Alkali- Silica Reaction (ASR) in Transportation Structures, Report No. FHWA-HIF-09-004, Federal Highway Administration, U.S. Department of Transportation, Washington DC, (2010) 154.

[134] S. Kandasamy, M.H. Shehata, The capacity of ternary blends containing slag and highcalcium fly ash to mitigate alkali silica reaction, Cem. Concr. Comp. 49 (2014) 92-99.

[135] J.H. Ideker, B.L. East, K.J. Folliard, M.D. Thomas, B. Fournier. The current state of the accelerated concrete prism test. Cem. Concr. Res. 40(4) (2010) 550-555.

[136] M.S. Islam, S. Akhtar, A critical assessment to the performance of alkali-silica reaction (ASR) in concrete, Canadian Chemical Transactions, 1(4) (2013) 253-266.

[137] E.R. Latifee, P.R. Rangaraju, Miniature concrete prism test: rapid test method for evaluating alkali-silica reactivity of aggregates, J. Mater. Civil. Eng. 27(7) (2014) 04014215.

[138] K. Yamada, S. Karasuda, S. Ogawa, Y. Sagawa, M. Osako, H. Hamada, M. Isneini, CPT as an evaluation method of concrete mixture for ASR expansion, Cons. Build. Mater. 64 (2014) 184-191.

[139] S.W. Supit, F.U Shaikh, P.K. Sarker, Effect of ultrafine fly ash on mechanical properties of high volume fly ash mortar, Constr. Build. Mater. 51(2014) 278-286.

[140] Y. Kawabata, K. Yamada, The mechanism of limited inhibition by fly ash on expansion due to alkali-silica reaction at the pessimum proportion, Cem. Concr. Res. 92 (2017) $1-15$.

[141] K. Turk, C. Kina, M. Bagdiken, Use of binary and ternary cementitious blends of FClass fly-ash and limestone powder to mitigate alkali-silica reaction risk, Constr. Build. Mater. 151 (2017) 422-427.

[142] M. Zeidan, A. Said, Alkali-Silica Reaction Mitigation Using Nano-silica and Fly Ash, In Nanotechnology in Construction Springer, Cham. (2015) 459-464.

[143] J.R. Wright, S. Shafaatian, F. Rajabipour, Reliability of chemical index model in determining fly ash effectiveness against alkali-silica reaction induced by highly reactive glass aggregates, Constr. Build. Mater. 64 (2014) 166-171.

[144] M. Isneini, Y. Sagawa, H. Hamada. D. Yamamoto, An Experimental Study on Mitigating Alkali Silica Reaction by Using Fly Ash (FA) in Combination with Silica 
Fume and Expanded Perlite Powder (EPP), In MATEC Web of Conferences, EDP Sciences, 47 (2016) 7.

[145] S. Wang, Cofired biomass fly ashes in mortar: reduction of alkali silica reaction (ASR) expansion, pore solution chemistry and the effects on compressive strength, Constr. Build. Mater. 82 (2015)123-132.

[146] S. Aydın, Ç. Karatay, B. Baradan, The effect of grinding process on mechanical properties and alkali-silica reaction resistance of fly ash incorporated cement mortars, Powder. Tech. 197(1-2) (2010) 68-72.

[147] A.G. Vayghan, J.R. Wright, F. Rajabipour, An extended chemical index model to predict the fly ash dosage necessary for mitigating alkali-silica reaction in concrete, Cem. Concr. Res. 82 (2016) 1-10.

[148] K. Afshinnia, P.R. Rangaraju, Effect of fineness of high lime fly ash on pozzolanic reactivity and ASR mitigation, Comp. Concr. 20(2) (2017) 197-204.

[149] F.U.A. Shaikh, S.W.M. Supit, P.K. Sarker, A study on the effect of nano silica on compressive strength of high volume fly ash mortars and concretes, Mater. Des. 60 (2014) 433-442.

[150] S.W.M. Supit, F.U.A. Shaikh, Durability properties of high volume fly ash concrete containing nano-silica, Mater. Struct. 48(8) (2015) 2431-2445.

[151] M. Zeidan, A.M. Said, Effect of colloidal nano-silica on alkali-silica mitigation, Journal of Sustainable Cement-Based Mater. 6(2) (2017) 126-138.

[152] A.K. Mukhopadhyay, K.W. Liu. Application of Nanotechnology to Control ASR in Portland Cement Concrete, In Nanotechnology in Construction Springer, Cham. (2015) 465-471.

[153] M.M. Norhasri, M.S. Hamidah, A.M. Fadzil, Applications of using nano material in concrete: A review, Constr. Build. Mater. 133 (2017) 91-97.

[154] E. Ghafari, H. Costa, E. Júlio, Critical review on eco-efficient ultra high performance concrete enhanced with nano-materials, Constr. Build. Mater. 101 (2015) 201-208.

[155] A. Beglarigale, H. Yazici, Mitigation of detrimental effects of alkali-silica reaction in cement-based composites by combination of steel microfibers and ground-granulated blast-furnace slag, J. Mater. Civil. Engg. 26(12) (2013) 04014091.

[156] J. Zapała-Sławeta, Alkali Silica Reaction In The Presence Of Metakaolin-The Significant Role of Calcium Hydroxide, IOP Conf. Ser.: Mater. Sci. Eng. 245 (2017) 022020 .

[157] K. Zheng, Pozzolanic reaction of glass powder and its role in controlling alkali-silica reaction, Cem. Concr. Comp. 67 (2016) 30-38.

[158] K. Afshinnia, P.R. Rangaraju, Influence of fineness of ground recycled glass on mitigation of alkali-silica reaction in mortars, Constr. Build. Mater. 81 (2015) 257-267.

[159] H. Du, K.H. Tan, Effect of particle size on alkali-silica reaction in recycled glass mortars, Constr. and Build. Mater. 66 (2014) 275-285.

[160] M. Boháč, M. Palou, R. Novotný, J. Másilko, D. Všianský, T. Staněk, Investigation on early hydration of ternary Portland cement-blast-furnace slag-metakaolin blends, Constr. Build. Mater. 64 (2014) 333-341. 
[161] E. Özbay, M. Erdemir, H.I. Durmuş, Utilization and efficiency of ground granulated blast furnace slag on concrete properties-a review, Constr. Build. Mater. 105 (2016) 423-434.

[162] İ. Ustabaş, A. Kaya, Comparing the pozzolanic activity properties of obsidian to those of fly ash and blast furnace slag, Constr. Build. Mater. 164 (2018) 297-307.

[163] M.A. Rahman, P.K. Sarker, F.U.A. Shaikh, A.K. Saha, Soundness and compressive strength of Portland cement blended with ground granulated ferronickel slag, Constr. Build. Mater. 140 (2017) 194-202.

[164] A.K. Saha, P.K. Sarker, Compressive strength of mortar containing ferronickel slag as replacement of natural sand, Procedia engineering, 171 (2017) 689-694.

[165] A.K. Saha, Effect of class F fly ash on the durability properties of concrete, Sust. Env. Res. 28(1) (2018) 25-31.

[166] A.K. Saha, P.K. Sarker, Durability characteristics of concrete using ferronickel slag fine aggregate and fly ash, Magazine. Concrete. Res. (2017) 1-10. https://doi.org/10.1680/jmacr.17.00260

[167] T. Ramlochan, M. Thomas, K.A. Gruber, The effect of metakaolin on alkali-silica reaction in concrete, Cem. Concr. Res. 30(3) (2000) 339-344.

[168] G. Lee, T.C. Ling, Y.L. Wong, C.S. Poon, Effects of crushed glass cullet sizes, casting methods and pozzolanic materials on ASR of concrete blocks, Constr. Build. Mater. 25(5) (2011) 2611-2618.

[169] J. Kim, J. Moon, J.W. Shim, J. Sim, H.G. Lee, G. Zi, Durability properties of a concrete with waste glass sludge exposed to freeze-and-thaw condition and de-icing salt, Constr. Build. Mater. 66 (2014) 398-402.

[170] K. Ramakrishnan, G. Pugazhmani, R. Sripragadeesh, D. Muthu, C. Venkatasubramanian, Experimental study on the mechanical and durability properties of concrete with waste glass powder and ground granulated blast furnace slag as supplementary cementitious materials, Constr. Build. Mater. 156 (2017) 739-749.

[171] S. Guo, Q. Dai, X. Sun, X. Xiao, R. Si, J. Wang, Reduced alkali-silica reaction damage in recycled glass mortar samples with supplementary cementitious materials, J. Clean. Product. 172 (2018) 3621-3633.

[172] K. Afshinnia, P. Rangaraju, Effectiveness of ground glass powder from recycled glass in mitigating alkali-silica reaction in concrete, J. Trans. Res. Board, 2508(10) (2015).

[173] J. Kim, C. Yi, G. Zi, Waste glass sludge as a partial cement replacement in mortar, Constr. Build. Mater. 75 (2015) 242-246.

[174] Z. Yao, T.C. Ling, P.K. Sarker, W. Su, J. Liu, W. Wu, J. Tang, Recycling difficult-totreat e-waste cathode-ray-tube glass as construction and building materials: A critical review, Renew. Sust. Energ. Rev. 81 (2018) 595-604. 
Table 1. Expansion of aggregates with different amorphous silica content.

\begin{tabular}{|c|c|c|c|c|c|c|c|}
\hline \multirow[b]{2}{*}{$\begin{array}{l}\text { Type of } \\
\text { aggregate }\end{array}$} & \multirow[b]{2}{*}{ Source } & \multirow[b]{2}{*}{$\begin{array}{c}\text { Amorphous } \\
\text { silica (\%) }\end{array}$} & \multicolumn{4}{|c|}{ Expansion (\%) } & \multirow[b]{2}{*}{ References } \\
\hline & & & $\left|\begin{array}{c}\mathrm{CPT} \\
(1 \text { year })\end{array}\right|$ & $\begin{array}{c}\text { Allowable } \\
\text { limit }\end{array}$ & $\begin{array}{c}\text { AMBT } \\
(14 \\
\text { days })\end{array}$ & $\begin{array}{c}\text { Allowable } \\
\text { limit }\end{array}$ & \\
\hline \begin{tabular}{|l} 
Dolomitic \\
limestone
\end{tabular} & \begin{tabular}{|c|} 
Pittsburgh \\
quarry, Kingston \\
\end{tabular} & 91.5 & 0.616 & \multirow{10}{*}{$\begin{array}{l}\mathrm{E} \leq 0.04 \\
{[\mathrm{ASTM}} \\
\mathrm{C} 1293]\end{array}$} & - & \multirow{10}{*}{$\begin{array}{l}\mathrm{E} \leq 0.1 \\
{[\text { ASTM }} \\
\mathrm{C} 1567]\end{array}$} & $\begin{array}{c}\text { Grattan-Bellew et al. } \\
{[13]}\end{array}$ \\
\hline $\begin{array}{l}\text { Chinese } \\
\text { limestone }\end{array}$ & China & 4.6 & 0.064 & & - & & $\begin{array}{c}\text { Grattan-Bellew et al. } \\
{[13]}\end{array}$ \\
\hline waste glass & Turkey & 71 & - & & 0.820 & & Topçu et al. [14] \\
\hline \begin{tabular}{|l} 
Sintered silica \\
fume
\end{tabular} & - & 85 & - & & 0.650 & & $\begin{array}{c}\text { Juenger \& Ostertag } \\
{[15]}\end{array}$ \\
\hline FNS & \begin{tabular}{|c|} 
SLN, \\
New Calidonia
\end{tabular} & 50 & - & & 0.653 & & Saha \& Sarker [17] \\
\hline Flint & \begin{tabular}{|l|} 
Thames Valley \\
\end{tabular} & 50 & 1.482 & & 0.610 & & Thomas et al. [40] \\
\hline Spratt & Ottawa & 29.7 & 0.275 & & 0.375 & & $\begin{array}{c}\text { Shehata \& Thomas } \\
{[55]}\end{array}$ \\
\hline Opal aggregate & CELITE, S.A. & 84 & - & & 0.890 & & $\begin{array}{l}\text { García-Lodeiro et al. } \\
{[56]}\end{array}$ \\
\hline Chert & Texas & 71.2 & 0.420 & & 0.700 & & Moser et al. [57] \\
\hline Glass & Canada & 73 & - & & 0.631 & & Shafaatian et al. [58] \\
\hline
\end{tabular}

Table 2. ASR expansions for different cement replacements by fly ash.

\begin{tabular}{|c|c|c|c|c|c|c|c|c|c|c|c|c|}
\hline \multirow{2}{*}{$\begin{array}{l}\text { Fly ash } \\
\text { type }\end{array}$} & \multirow{2}{*}{ Test type } & \multicolumn{10}{|c|}{ Cement replacement level (\%) } & \multirow{2}{*}{ References } \\
\hline & & 10 & 15 & 20 & 25 & 30 & 35 & 40 & 45 & 50 & 60 & \\
\hline Class F & AMBT & - & - & - & - & 0.08 & - & - & - & - & - & Saha \& Sarker [17] \\
\hline Class C & \multirow{2}{*}{ CPT } & - & - & - & - & 0.14 & - & - & 0.06 & - & 0.03 & \multirow{2}{*}{ Shehata \& Thomas [19] } \\
\hline Class F & & - & 0.08 & 0.04 & - & - & - & - & - & - & - & \\
\hline Class F & AMBT & 0.55 & - & 0.18 & - & 0.06 & - & - & - & - & - & Choi \& Choi [31] \\
\hline Class C & \multirow{2}{*}{$\mathrm{CPT}$} & - & - & 0.123 & - & 0.10 & - & 0.068 & - & 0.042 & - & \multirow{2}{*}{ Shehata \& Thomas [55] } \\
\hline Class F & & - & 0.083 & 0.043 & 0.03 & - & - & - & - & - & - & \\
\hline Class F & AMBT & - & - & - & - & 0.03 & - & - & - & - & - & García-Lodeiro et al. [56] \\
\hline Class C & AMBT & - & - & - & $\begin{array}{c}0.48 \\
5\end{array}$ & - & - & - & - & - & - & Moser et al. [57] \\
\hline Class C & \multirow{2}{*}{ AMBT } & - & - & 0.41 & - & 0.38 & - & - & - & - & - & \multirow{2}{*}{ Esteves et al. [94] } \\
\hline Class F & & - & - & 0.38 & - & 0.33 & - & - & - & - & - & \\
\hline Class C & \multirow{2}{*}{ AMBT } & - & - & 0.23 & - & - & 0.11 & - & - & - & - & \multirow{2}{*}{ Shon et al. [95] } \\
\hline Class F & & - & - & 0.27 & - & - & 0.10 & - & - & - & - & \\
\hline Class F & AMBT & 0.15 & - & - & - & 0.12 & - & - & - & 0.07 & - & Awal \& Hussin [96] \\
\hline
\end{tabular}


Figures

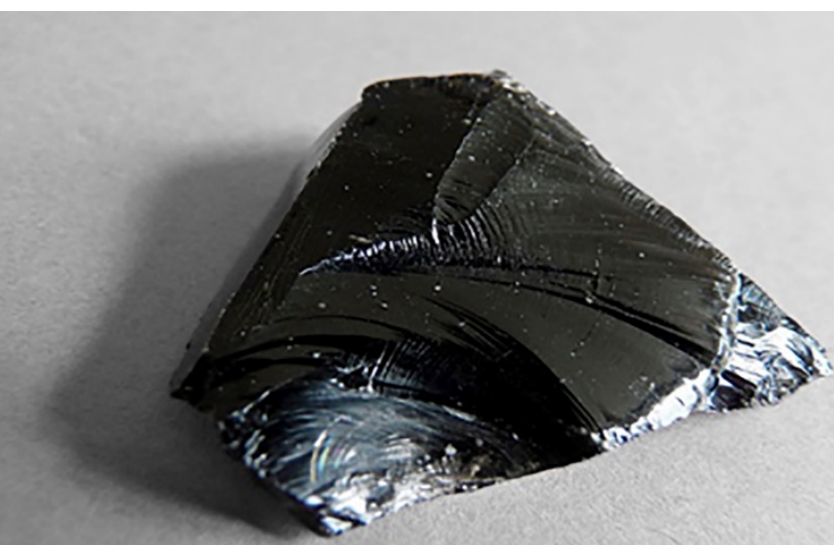

1142

1143

(c)

(b)
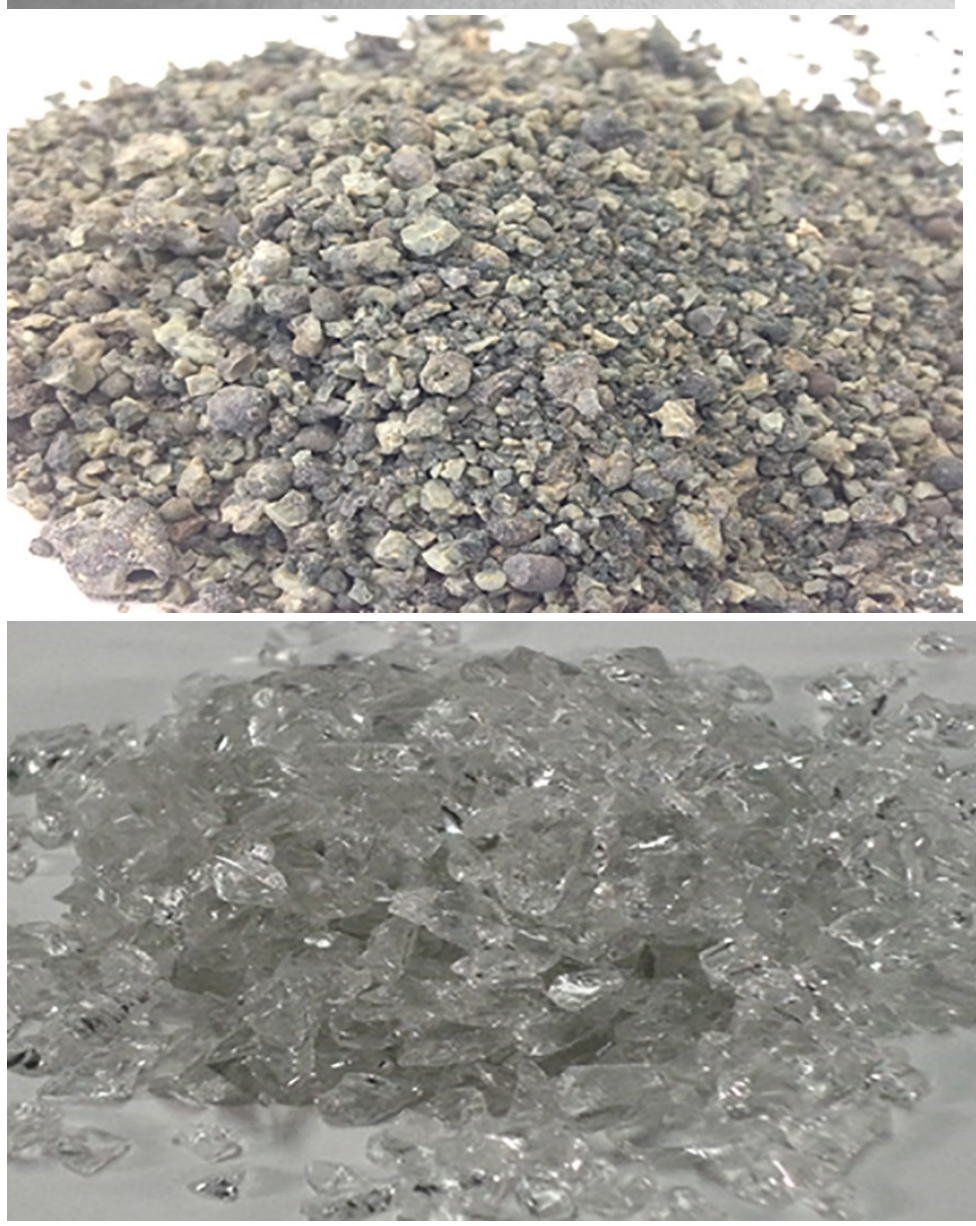

1145 Fig. 1. (a) Obsidian, volcanic glass [62] (b) Nickel slag [63] and (c) Waste glass aggregate 1146 [64]. 


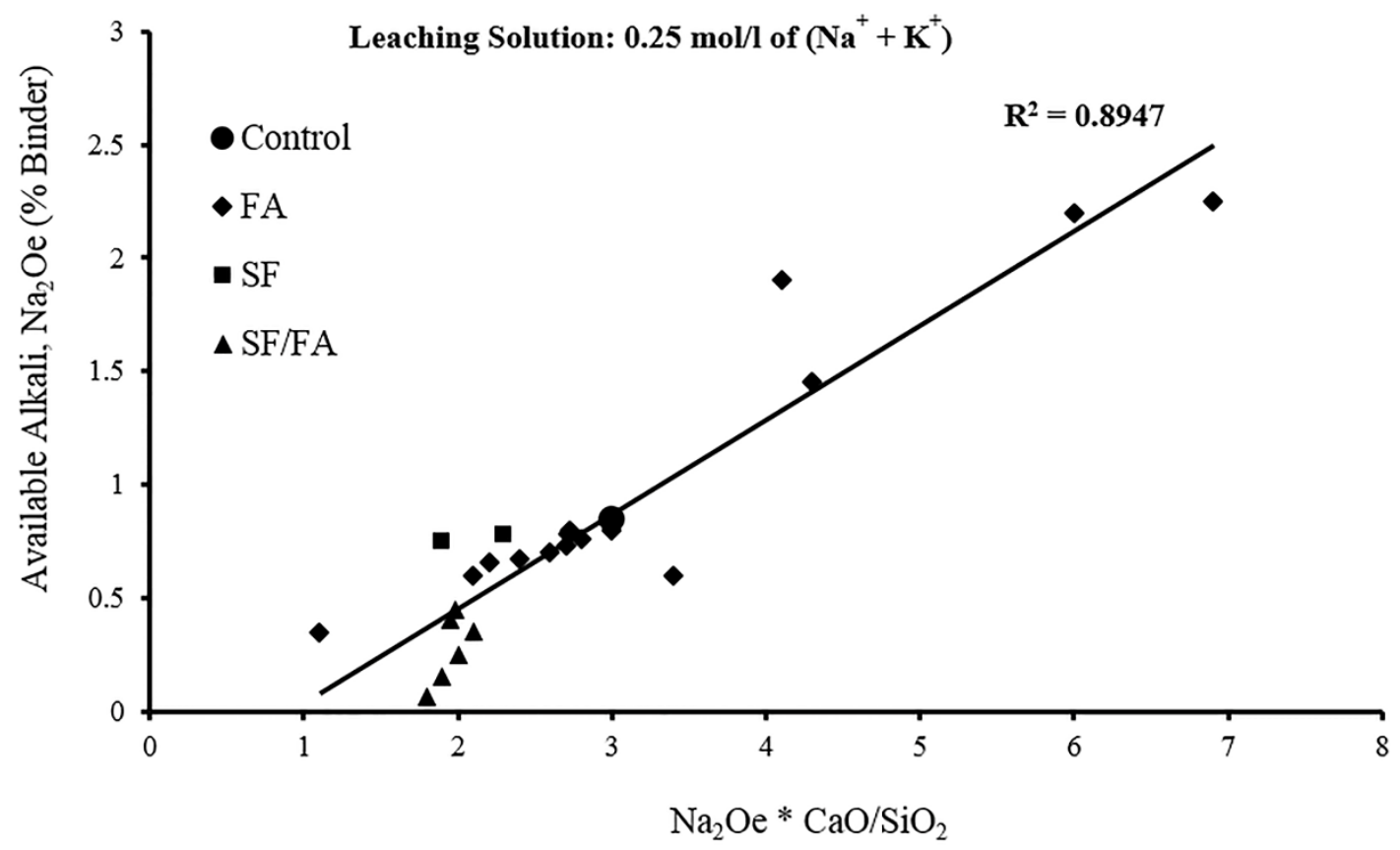

1148 Fig. 2. Effect of binder composition on the alkali release in pore solution [80].

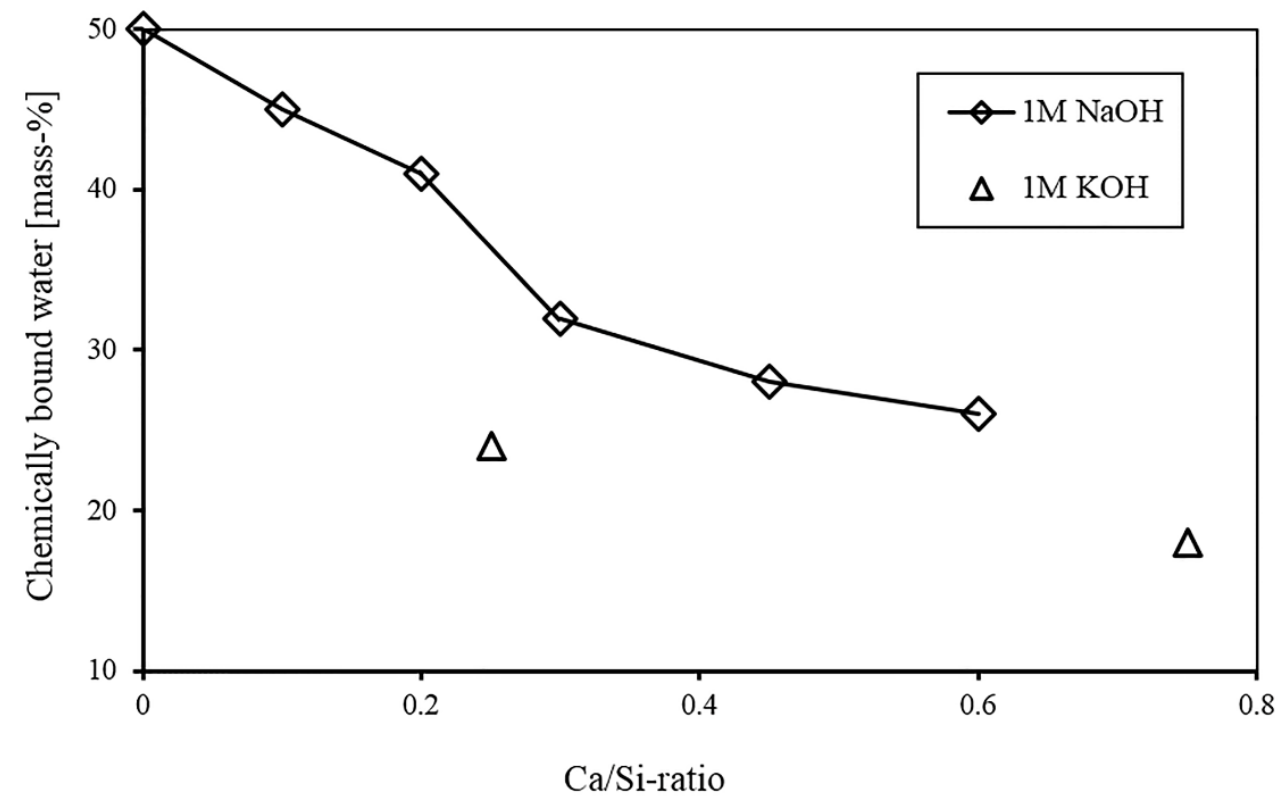

(a) 


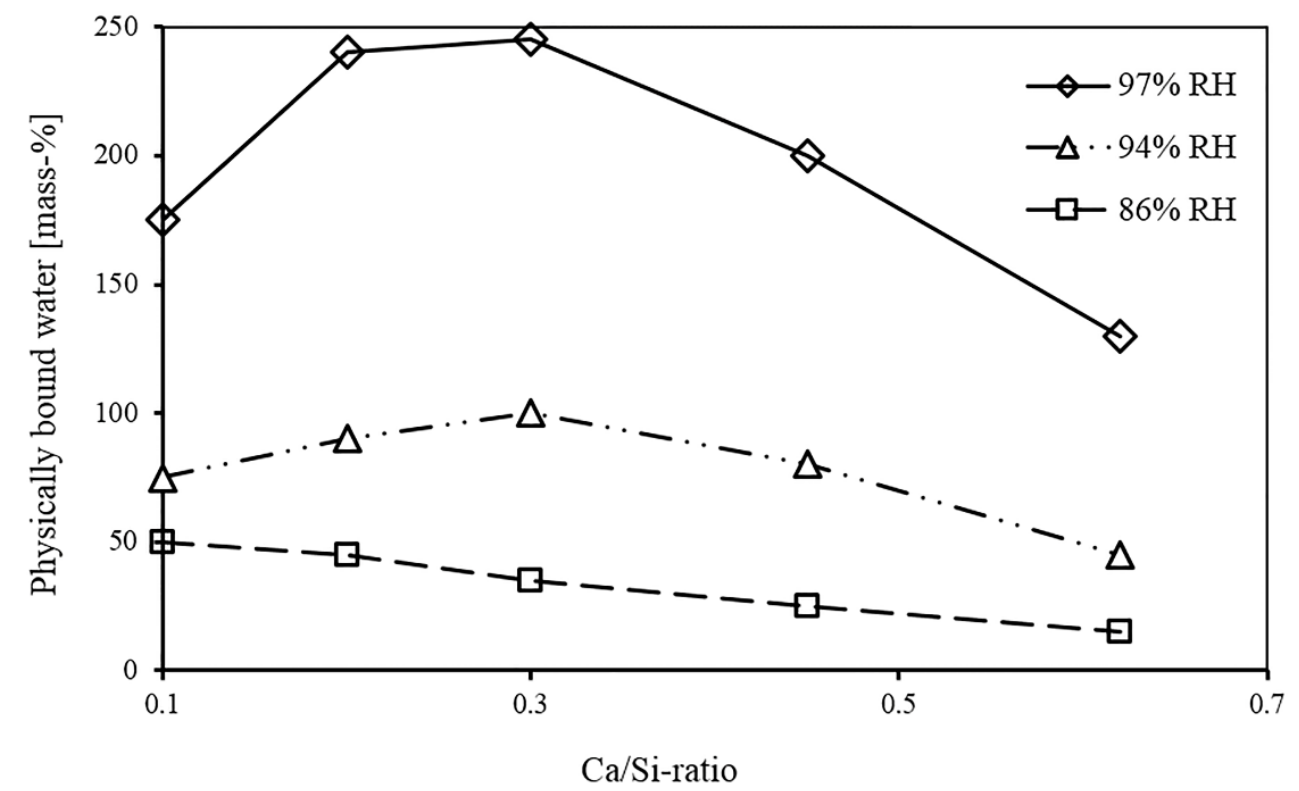

(b)

1151 Fig. 3. Water binding capability by ASR gel with respect to $\mathrm{Ca} / \mathrm{Si}$ ratio (a) chemically bound water Vs Ca/Si-ratio and (b) physically bound water Vs Ca/Si-ratio [90].

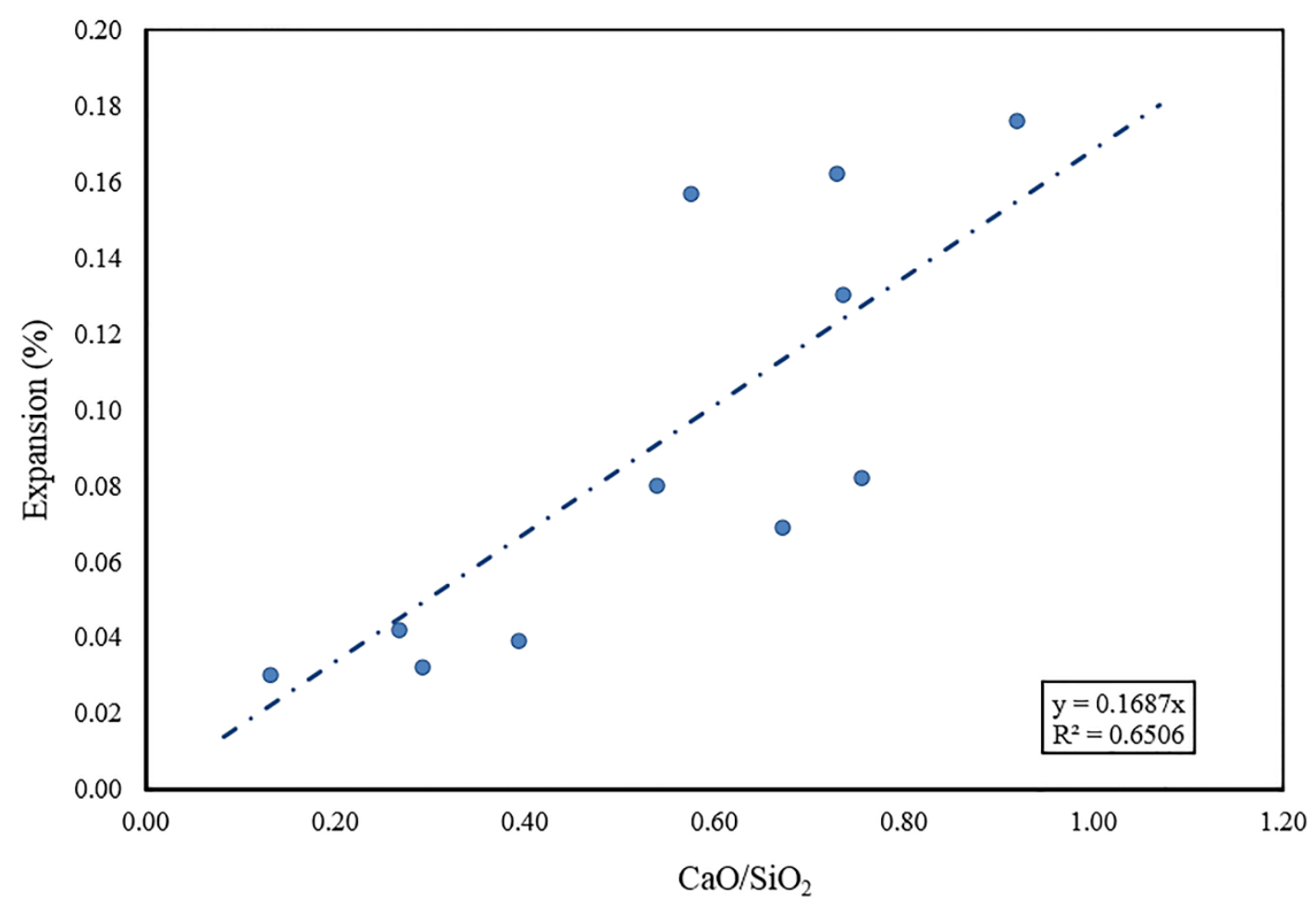

1154 Fig. 4. Correlation between ASR expansion and $\mathrm{CaO} / \mathrm{SiO}_{2}$ of fly ash [55]. 


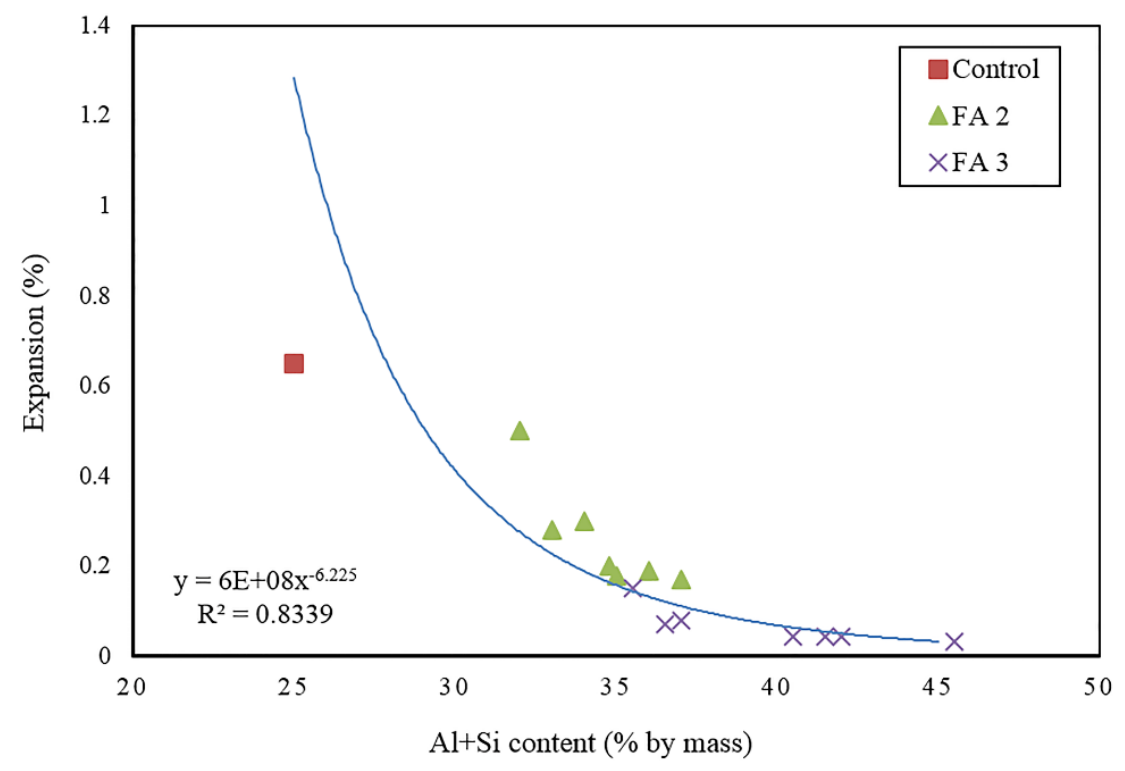

1156

(a)

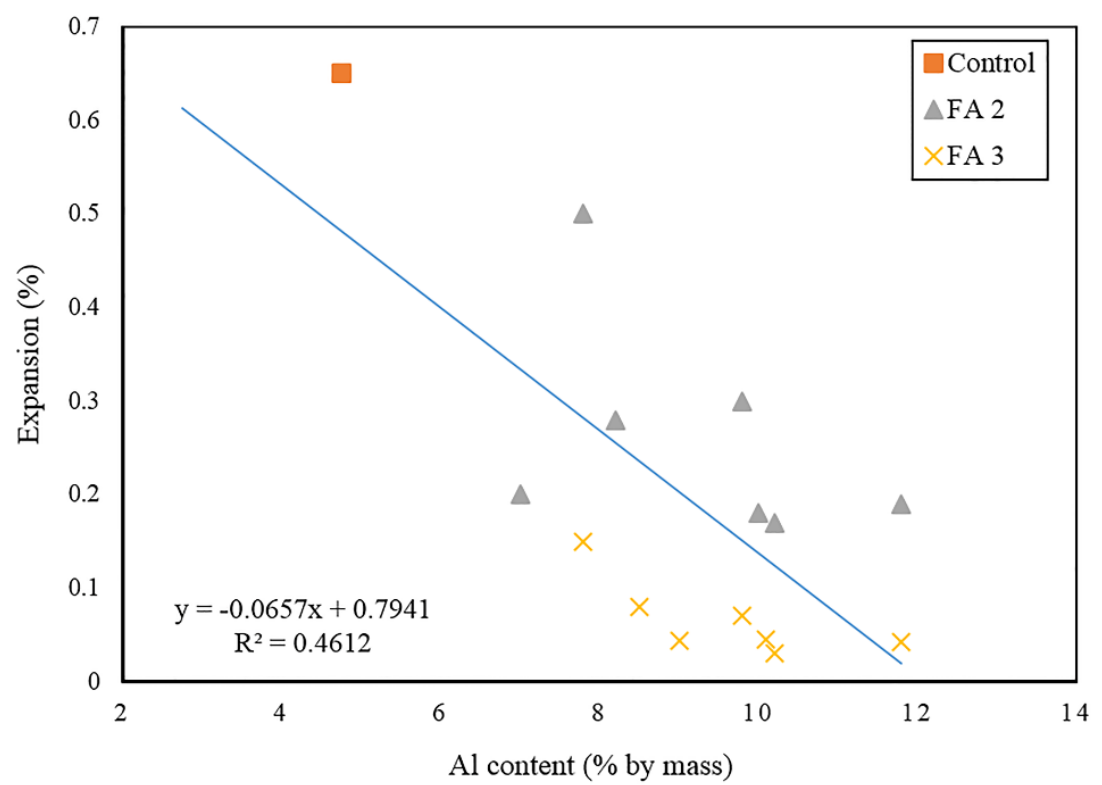

(b)

1158 Fig. 5. Relationship between (a) expansion and total Al+Si content and (b) expansion and only 1159 Al content of fly ash [98]. 


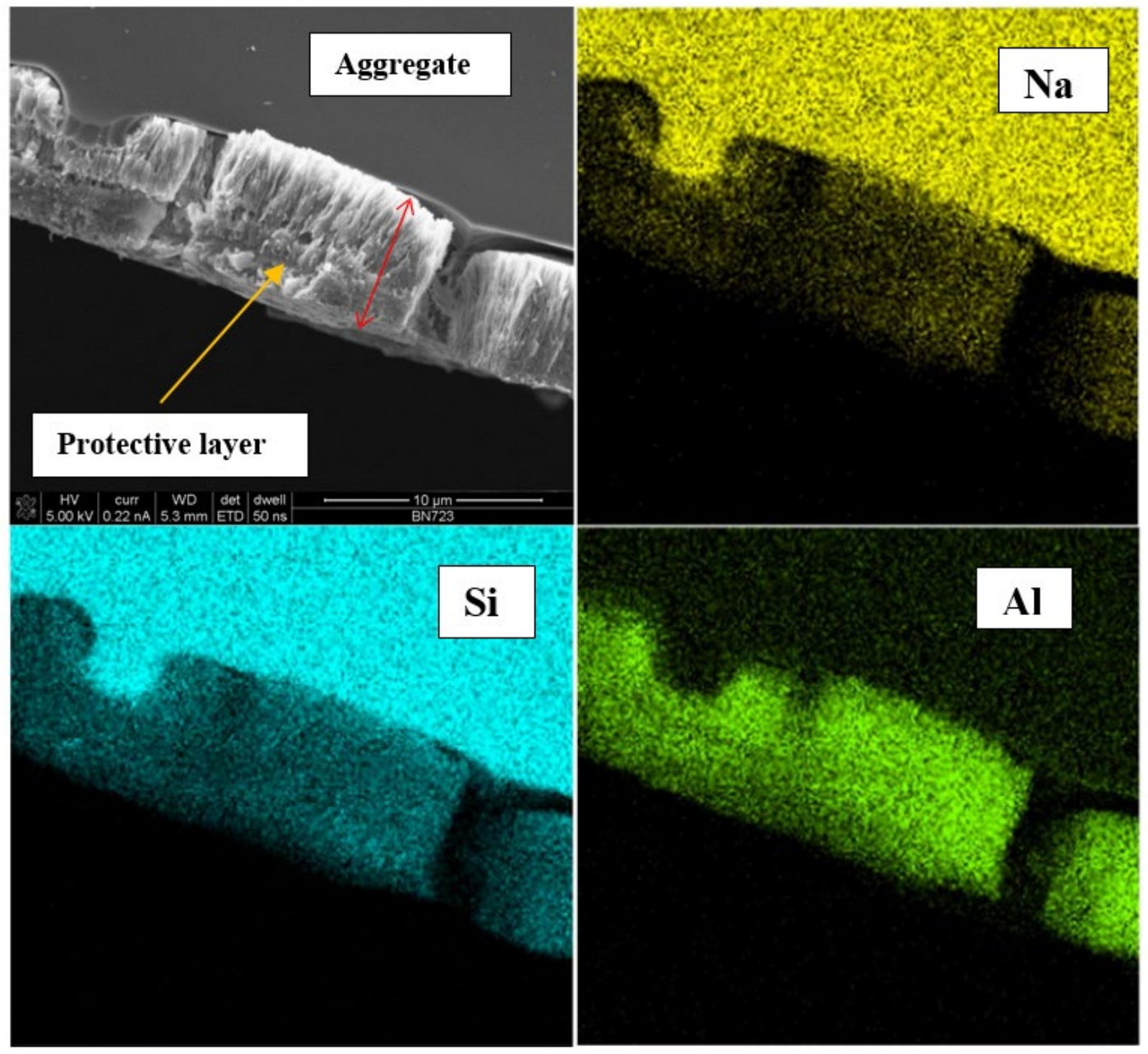

1161 Fig. 6. SEM and EDS mapping of $\mathrm{Al}, \mathrm{Si}$ and $\mathrm{Na}$ elements in the glass slides surface reaction 1162 product in presence of $\mathrm{Al}(\mathrm{OH})_{3}[100]$. 


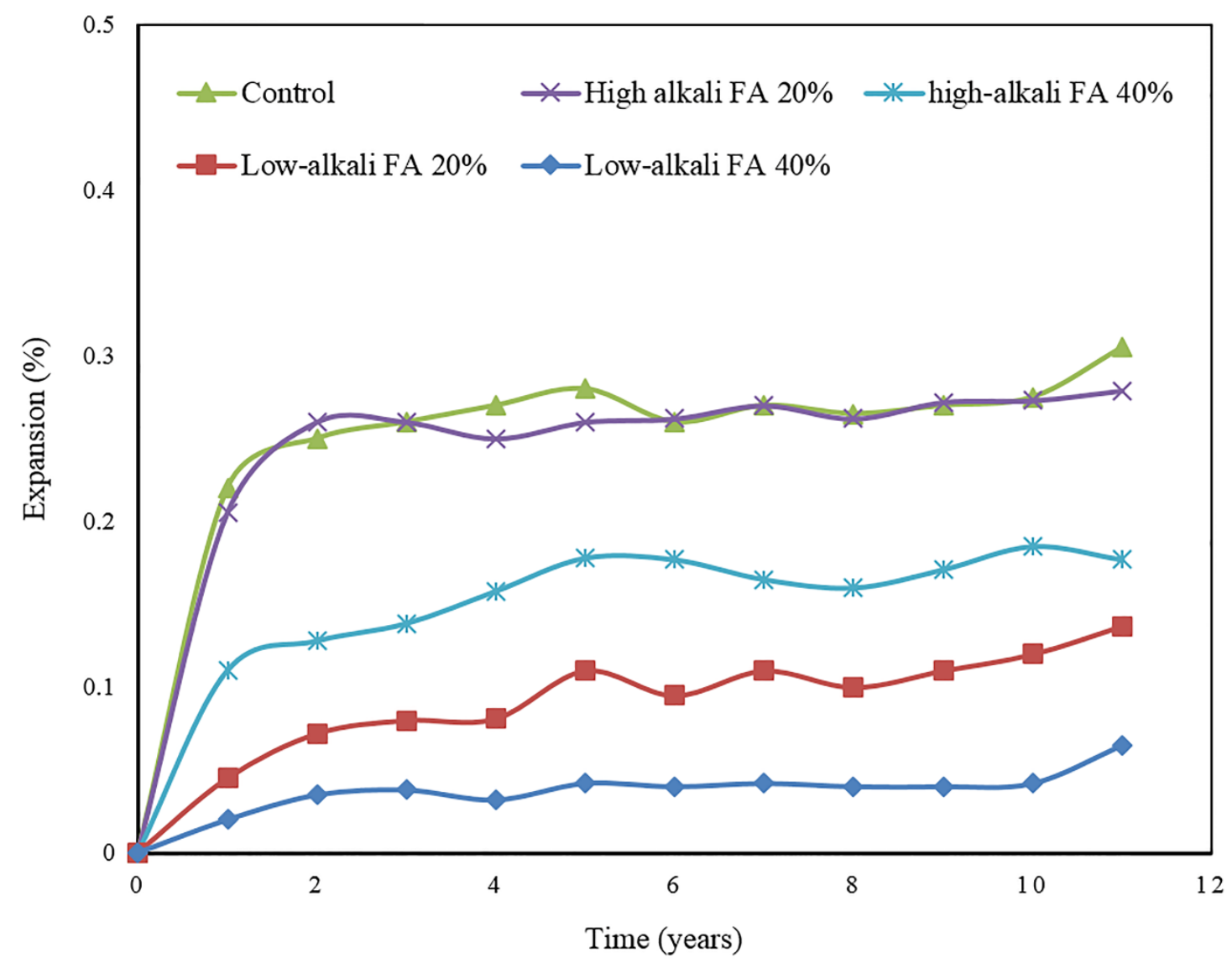

1164 Fig. 7. Expansions of fly ash mixed samples cured at $38^{\circ} \mathrm{C}$ and $100 \% \mathrm{RH}$ [103]. 


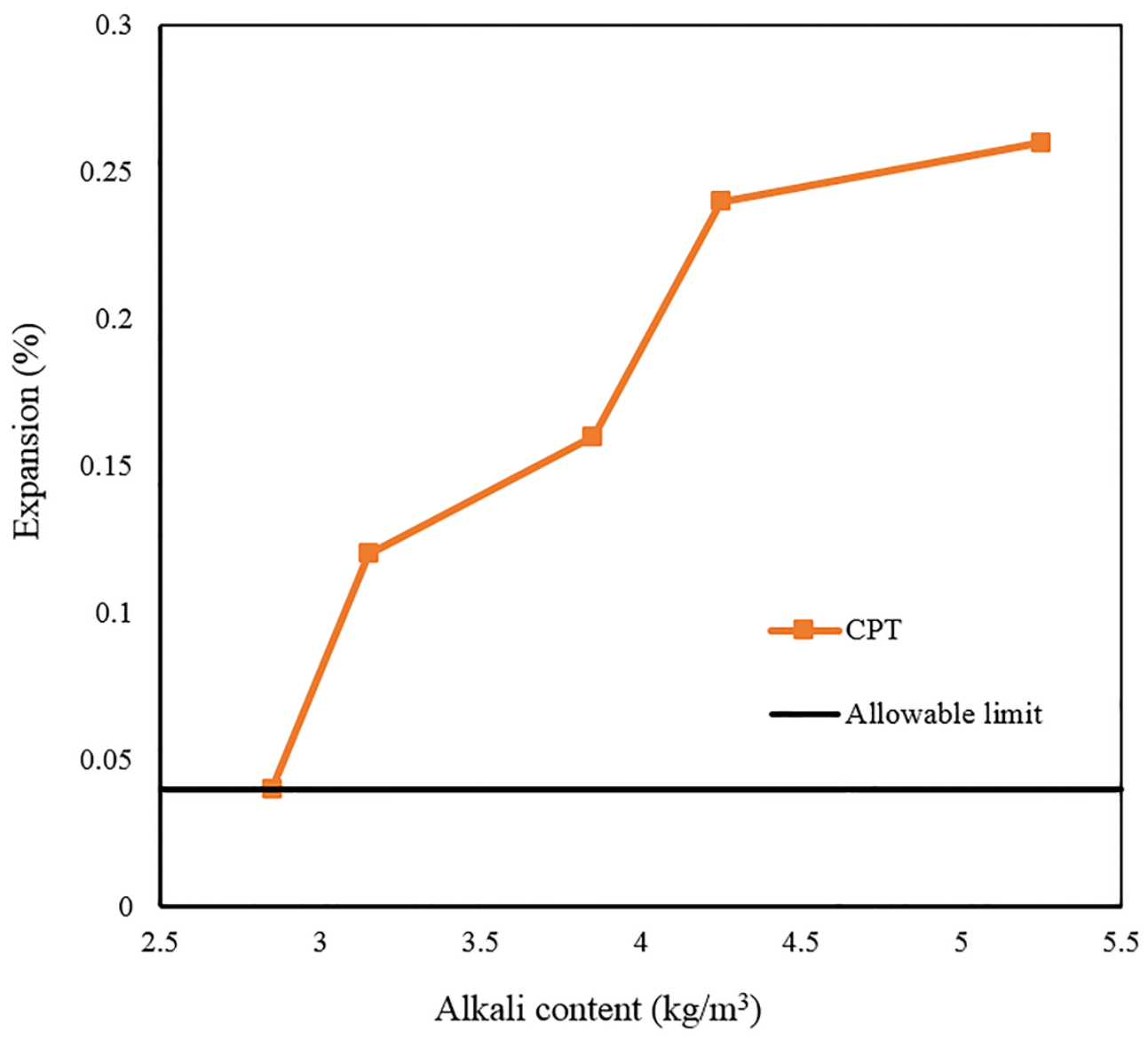

1165

1166 Fig. 8. Effect of alkali content of fly ash on the expansion of concrete after two years of testing $1167[55]$. 

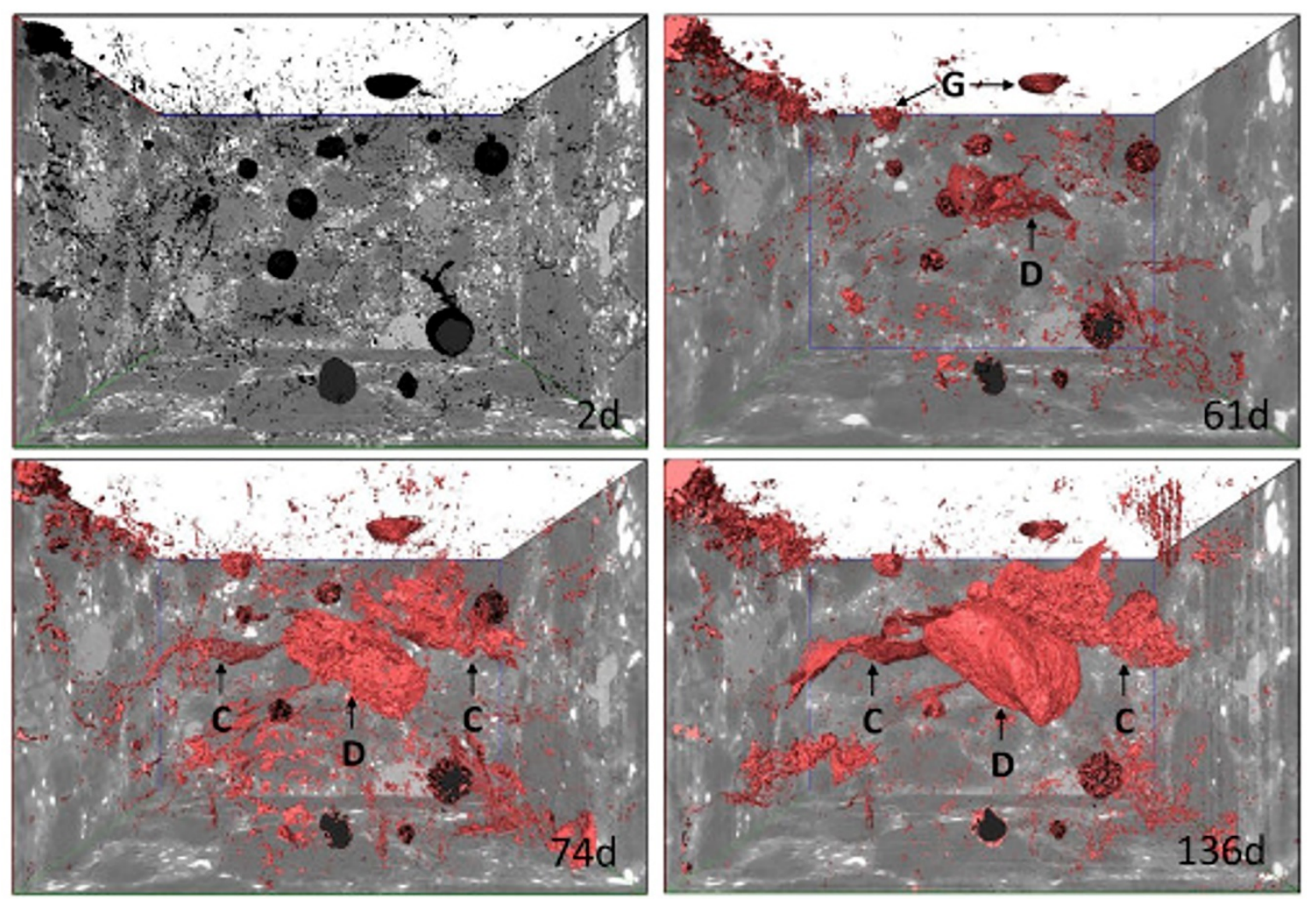

Fig. 9. 3D image of ASR affected samples after 2, 61, 74 and 136 days in $1 \mathrm{M} \mathrm{NaOH}$ solution at $50{ }^{\circ} \mathrm{C}$ (Initial air gaps are black and the ASR gel is pink) [104]. 


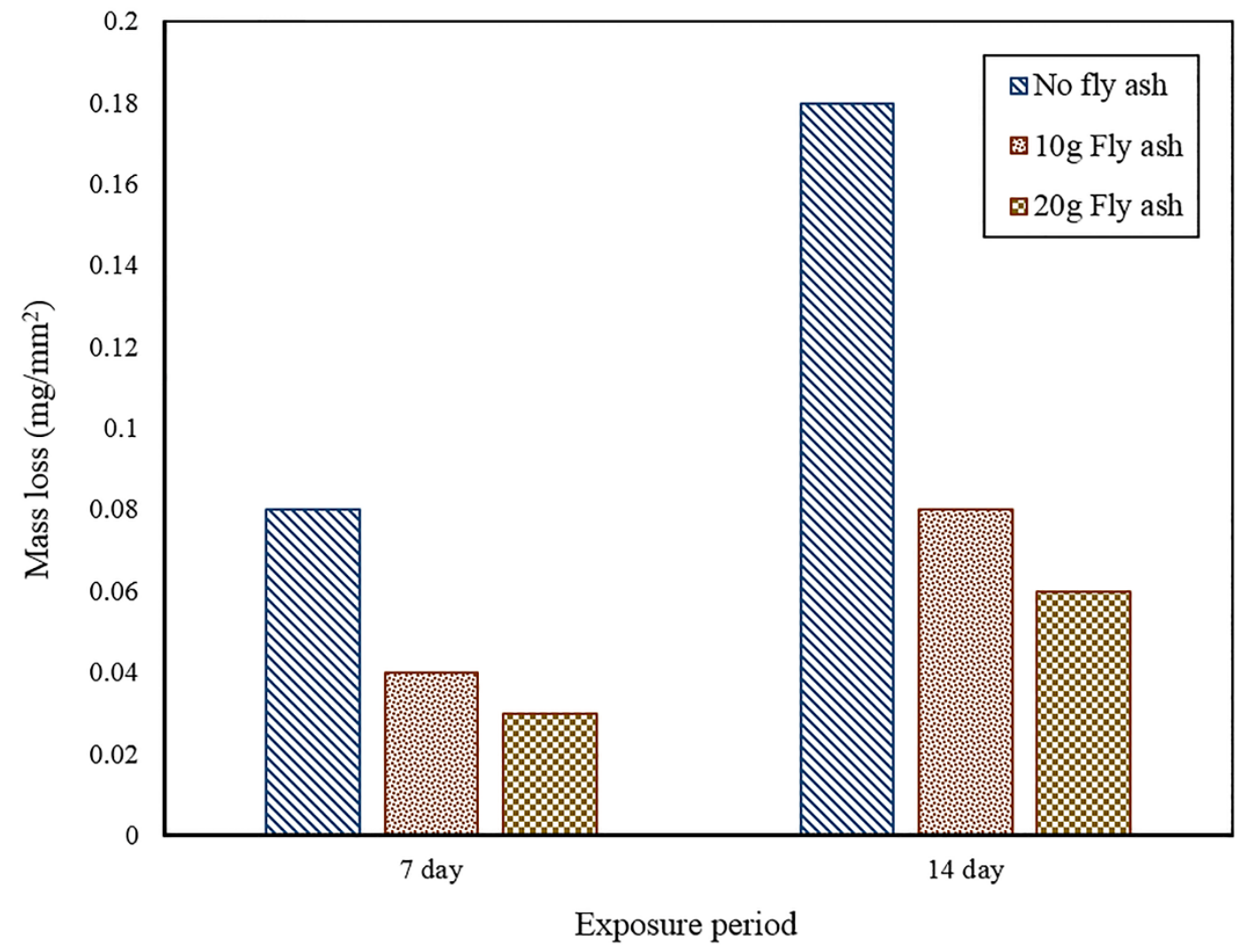

1171

1172 Fig. 10. Aggregate dissolution by $\mathrm{NaOH}$ exposure. [58]. 


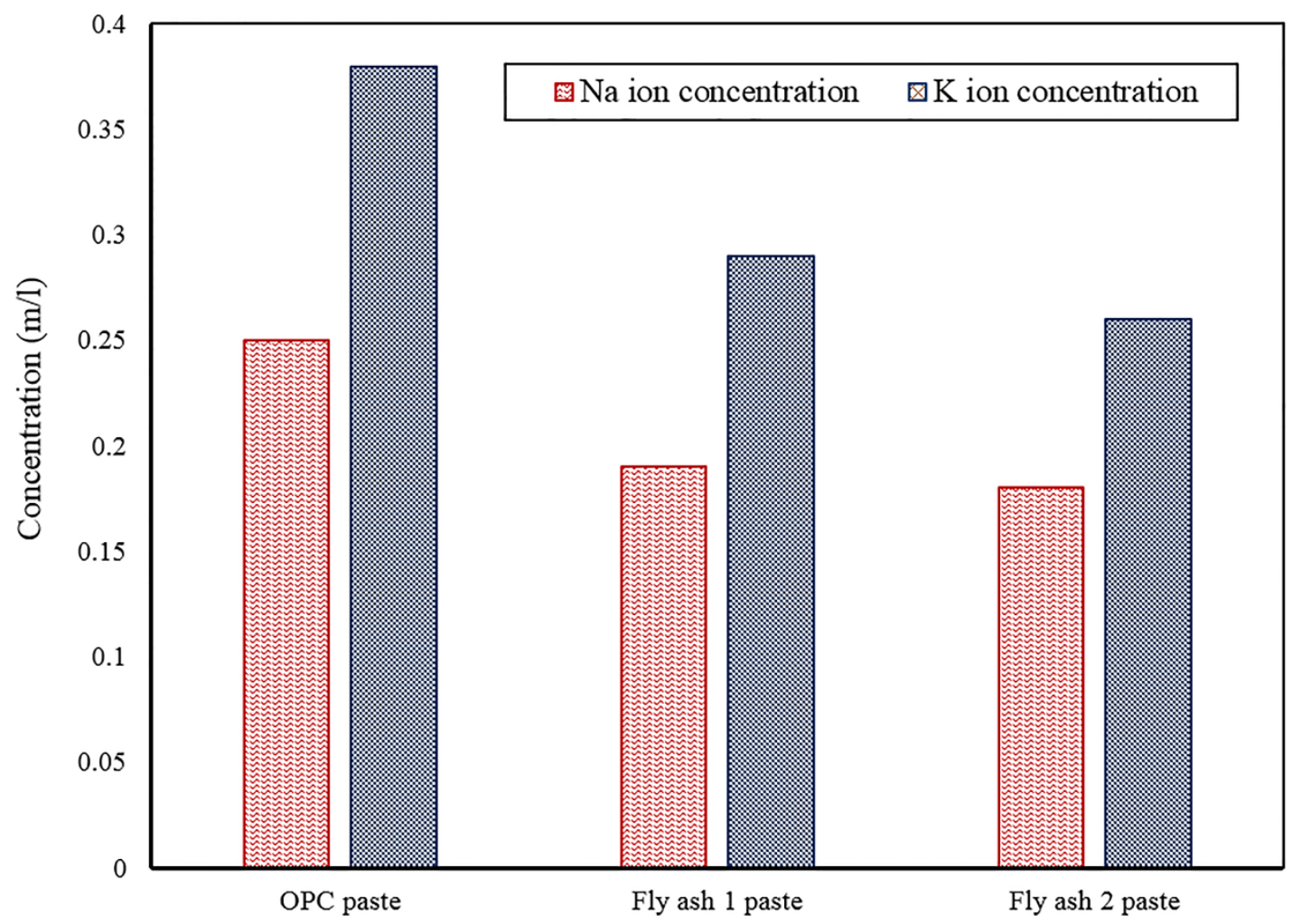

1173

1174 Fig. 11. Alkali concentration in pore solution after 10 days of curing [105].

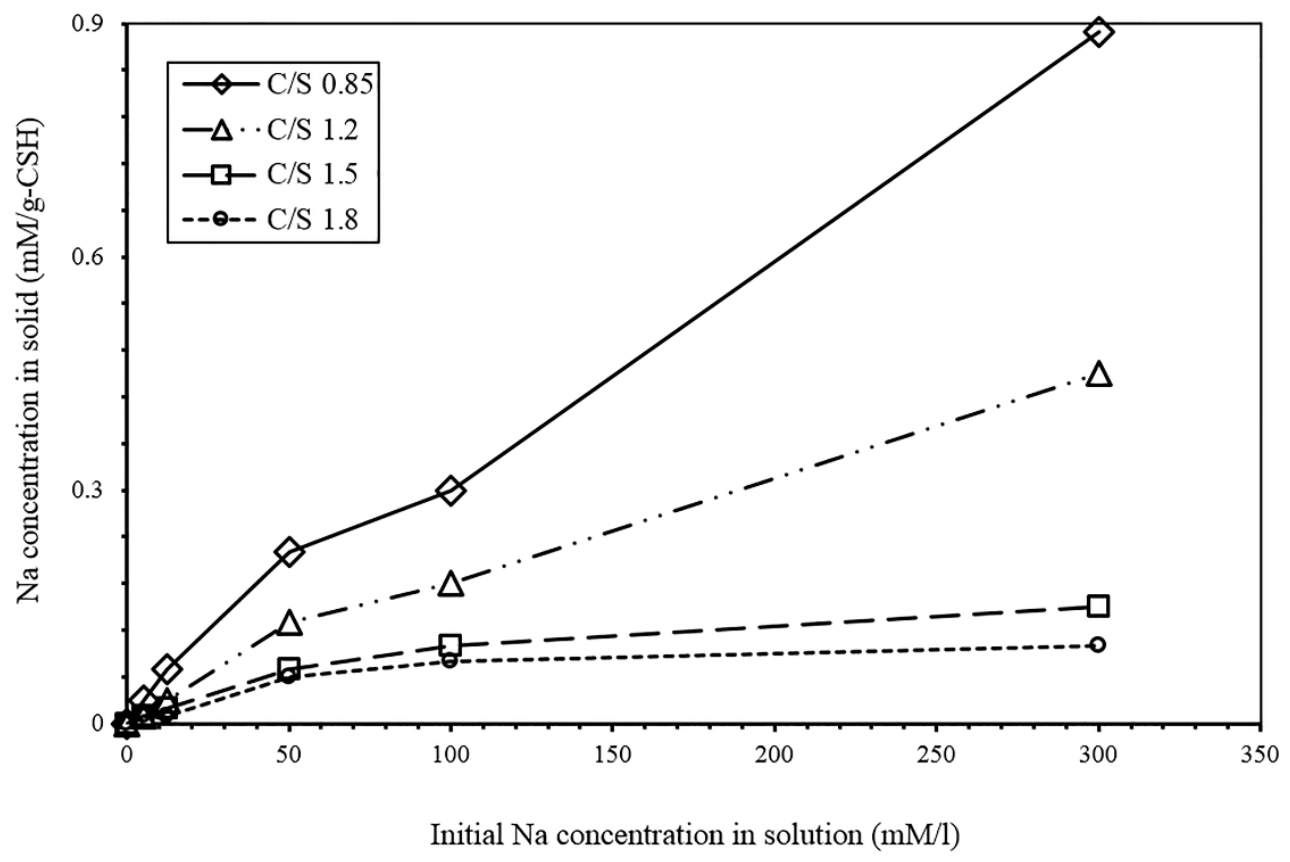

(a) 


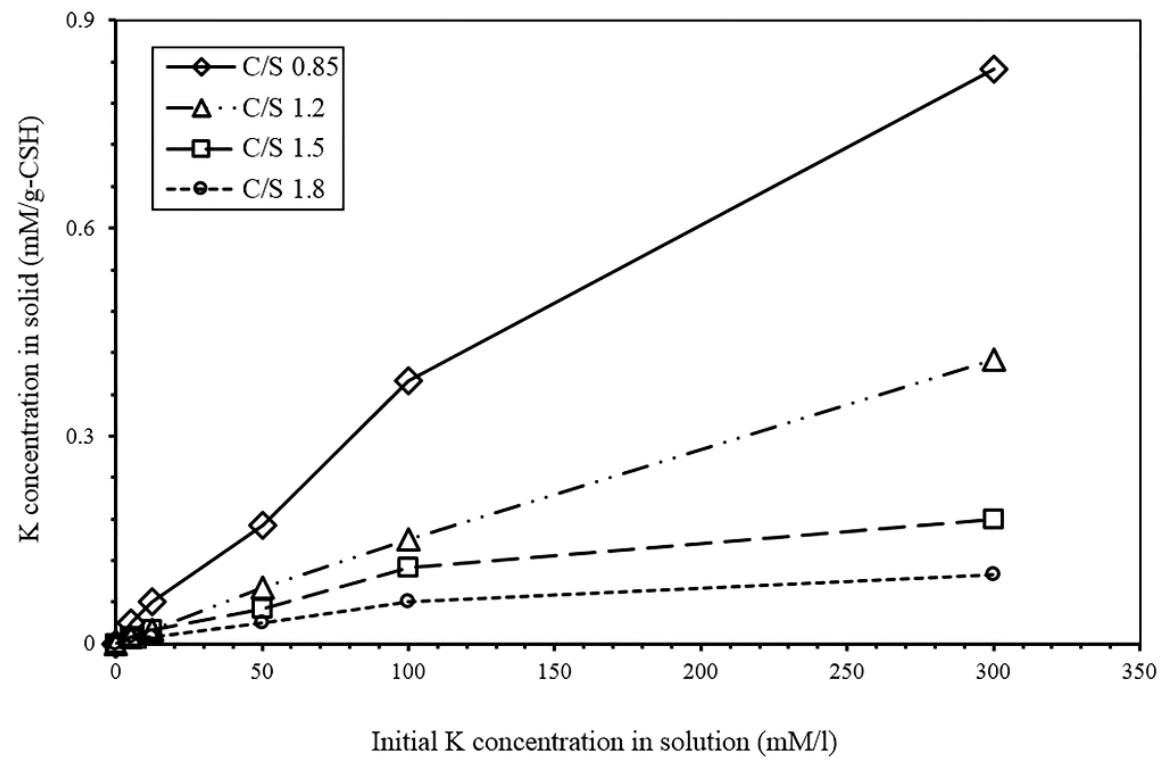

(b)

1177 Fig. 12. The concentration of (a) sodium and (b) potassium ion in C-S-H with respect to C/S 1178 [82].

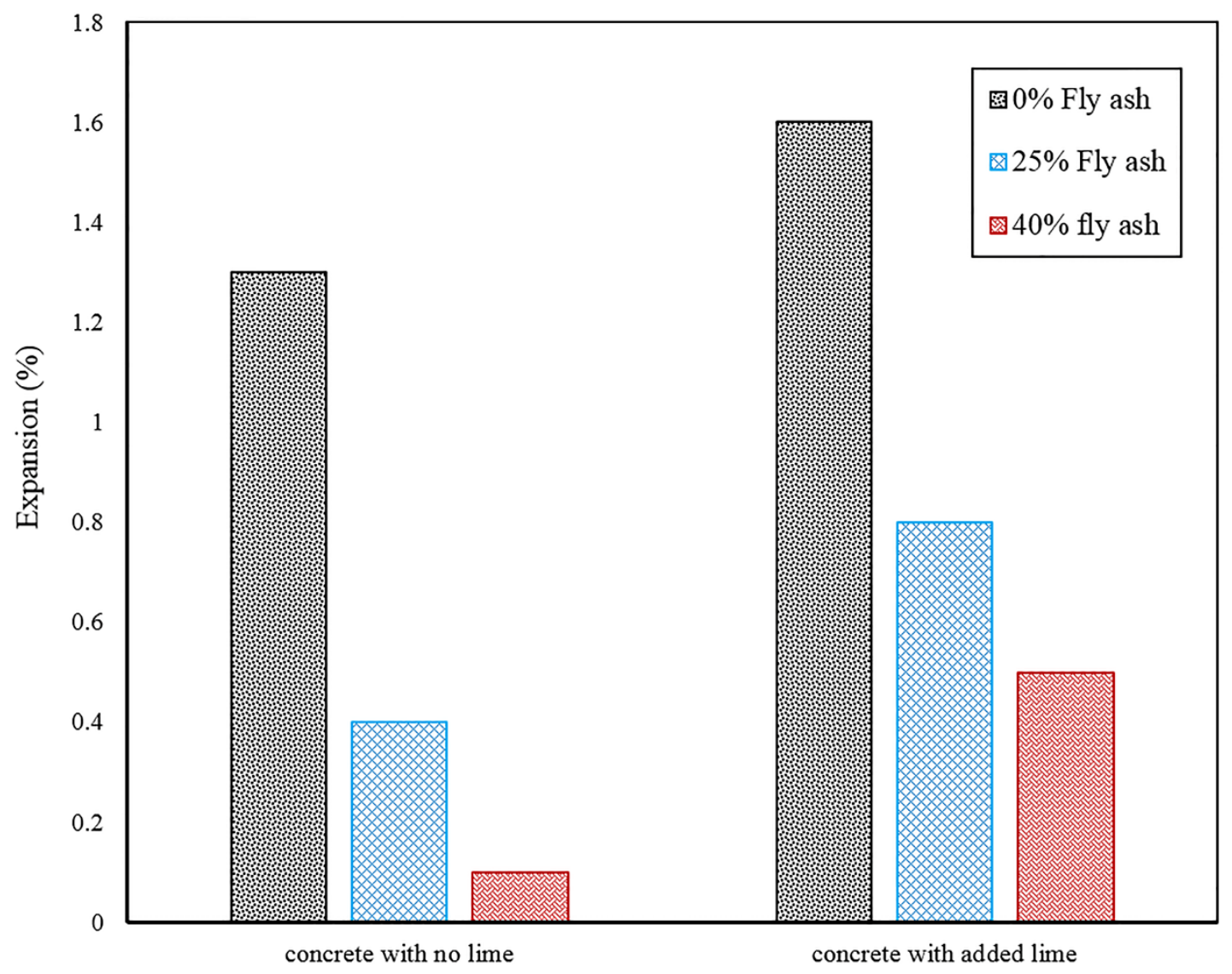

1180 Fig. 13. Effect of lime on the expansion of fly ash mixed concrete [109]. 


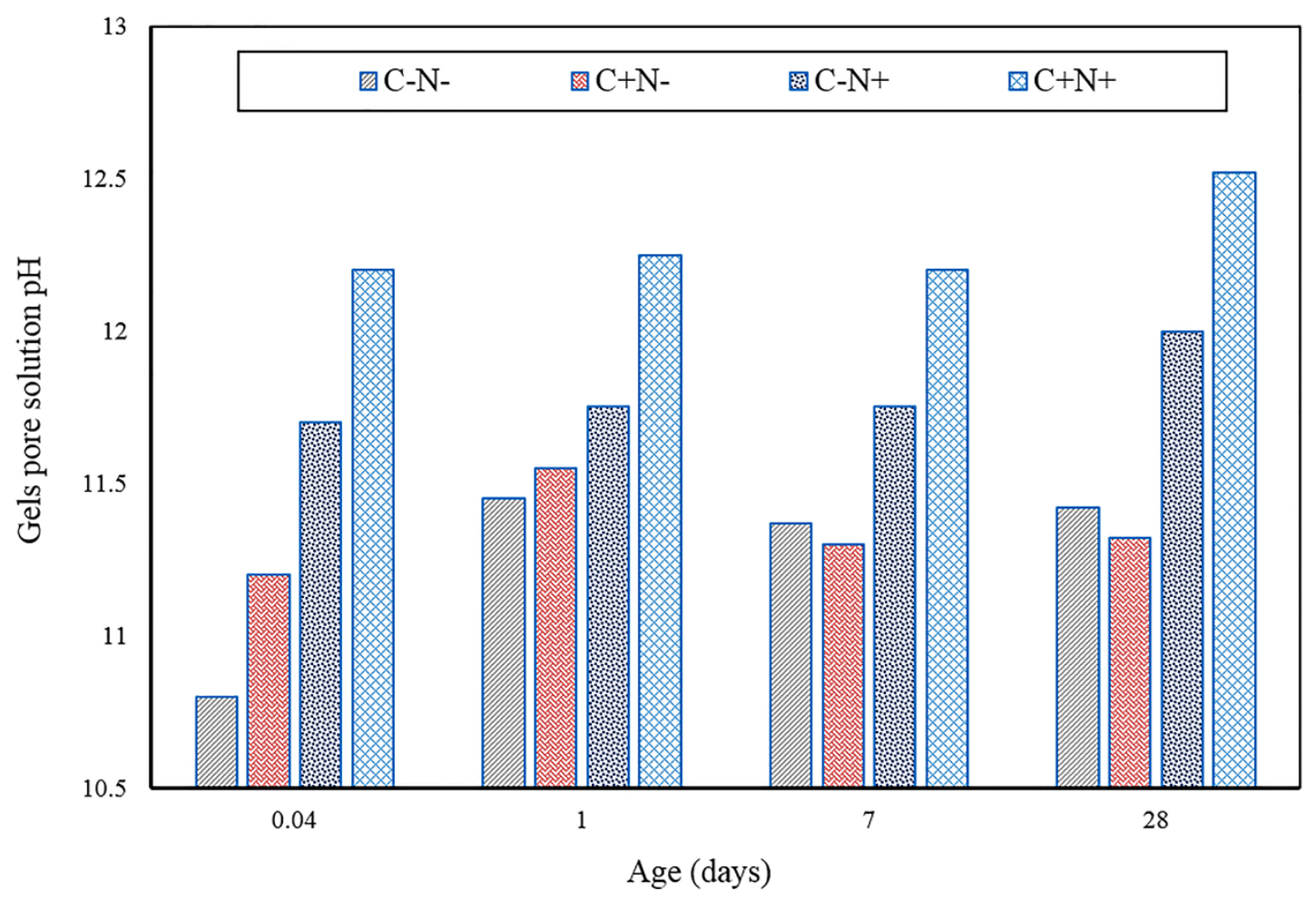

1181

1182 Fig. 14. $\mathrm{pH}$ of the gel pores with respect to calcium and sodium content [51]. 